\title{
LA RESTAURACIÓN DE LA IGLESIA DE SANT QUIRZE DE PEDRET (BARCELONA, ESPAÑA)
}

\author{
(RESTORATION OF SANT QUIRZE DE PEDRET CHURCH, BARCELONA, SPAIN)
}

Antoni González Moreno - Navarro, Arquitecto

Fecha de recepción:29-VIII-96

Jefe del Servicio del Patrimonio Arquitectónico Local de la Diputación de Barcelona

$128-65$

\begin{abstract}
RESUMEN
Sant Quirze de Pedret es una pequeña iglesia de finales del primer milenio propiedad del ayuntamiento de Berga (provincia de Barcelona). Es conocida internacionalmente por las pinturas románicas y prerrománicas halladas en 1922 y 1937, conservadas en Barcelona y Solsona. La evolución de su fábrica ha sido, a menudo, origen de polémica. La primera restauración realizada por la Diputación de Barcelona (1959. 1964), sin embargo, evidenció las sucesivas fases de construcción. Transcurridos 25 años fue necesaria una nueva restauración, también a cargo de la Diputación. Se completaron los estudios históricos y la reconstrucción formal iniciada en 1959 y las pinturas murales (originales o reproducidas) han vuelto a decorar los muros.
\end{abstract}

\section{SUMMARY}

Sant Quirze de Pedret is a small church built on late first millenium of our era. It belongs to the Town Council of Berga (province of Barcelona). Its Romanesque and preRomanesque paintings, found in 1922 and 1937 and kept in Barcelona and Solsona, enjoy international recognition. However, the first restoration carried out by the province county council of Barcelona (1959-1964) evidenced the successive phases of construction, and the evolution of its masonry is often subject to polemics. Twenty five years later a new restoration was needed. To complete the reconstruction initiated in 1959 and after thorough historical studies, mural paintings (originals and reproductions) are once again decorating its walls.
La iglesia de Sant Quirze de Pedret es propiedad del ayuntamiento de Berga (provincia de Barcelona). Se halla a tan sólo 3 kilómetros de la ciudad, pero pertenece al vecino municipio de Cercs. Es uno de los pocos edificios del primer milenio de nuestra Era que se conservan en Cataluña $\mathrm{y}$, como tal, uno de los monumentos más conocidos y apreciados, no sólo por la comunidad científica, sino por la ciudadanía en general.

Se sabe poco de los orígenes de la arquitectura de Pedret. Se ha dicho que la iglesia que conocemos perteneció a un monasterio (incluso se aventuró que se tratara de un cenobio femenino de la orden de san Benito), mas con certeza documentada sólo se sabe que desdeel siglo XI tuvo párroco. Mejor estudiadas han sido las pinturas murales que hicieron famoso al templo. Desde que en 1887 se diera la primera noticia de su existencia en el ábside sur, la comunidad científicales prestó gran atención. El historiador Joan Ainaud de Lasarte reconoce en el llamado Maestro de Pedret, autor anónimo del conjunto pictórico románico datado como de finales del siglo XI, "una de las primeras y mejores pruebas del conocimiento en la Cataluña medieval de las grandes corrientes internacionales de la pintura."1

En 1922, una vez adquiridas las pinturas por la Junta de Museos de Barcelona, fueron arrancadas y trasladadas a la sede del actual Museu Nacional d'Art de Catalunya en Barcelona, dondeahora sehallan expuestas, por cierto quede forma poco conveniente, tras la desafortunada reforma del museo dirigida por la arquitecta italiana Gae Aulenti. Al 
descubrimiento de ese magnífico conjunto pictórico se sumaron poco después nuevos hallazgos. En 1937, en plena guerra civil española, dentro de la campaña de protección del patrimonio artístico, fueron descubiertas otras pinturas románicas en la nave central y en el ábside mayor. Fue al arrancar éstas cuando aparecieron las pinturas prerrománicas del siglo X: el celebre Orant, personaje masculino con barba, túnica y brazos extendidos en actitud, posiblemente, de orar, rodeado por un círculo decorado con motivos en zig-zag, y el Cavaller, armado con lanza y estandarte. Los conjuntos pictóricos, arrancados en 1937, fueron trasladados en 1940, una vez acabada la guerra civil, al actual Museo Diocesano y Comarcal de Solsona.

La historia constructiva del templo no mereció hasta hace pocotiempotantaatención comola de las pinturas. La escasez de documentos y la ausencia de estudios arqueológicos hicieron que durante casi un siglo los inicios de la construcción del templo (sus etapas anteriores al románico), fueran objeto de hipótesis erróneas. Los trabajos más significativos publicados entre 1887 y 1962 sugieren o afirman que las tres naves de la iglesia fueron construidas de una sola vez ${ }^{2}$.

Camil Pallàs ${ }^{3}$, director de la restauración iniciada en 1959, fue el primero en apoyar la hipótesis de dos fases iniciales sucesivas, y se justifica en la investigación arqueológica hecha entonces, de la que da noticia. Los datos que hoy poseemos nos permiten afirmar que la primera construcción de Pedret, alzada en el siglo IX, fue de naveúnica con cabecera trapezoidal y que en el siglo $\mathrm{X}$ el templo fue ampliado a tres naves con cabecera de tres ábsides. Las tres naves fueron comunicadas mediante arcos de herradura. El edificio sufrió después cambios notables. En el siglo XI, cuando se construyó un edificio cenobial a escasos metros del templo éste fue decorado con los frescos. En el XIII, momento en que se eliminó buena parte de la nave sur -derruida poco tiempo antes-, se abrió la portada románica y la cubierta de madera (destruida posiblemente por un incendio) fue sustituida por una bóveda, lo que obligó a engrosar los muros. En el siglo

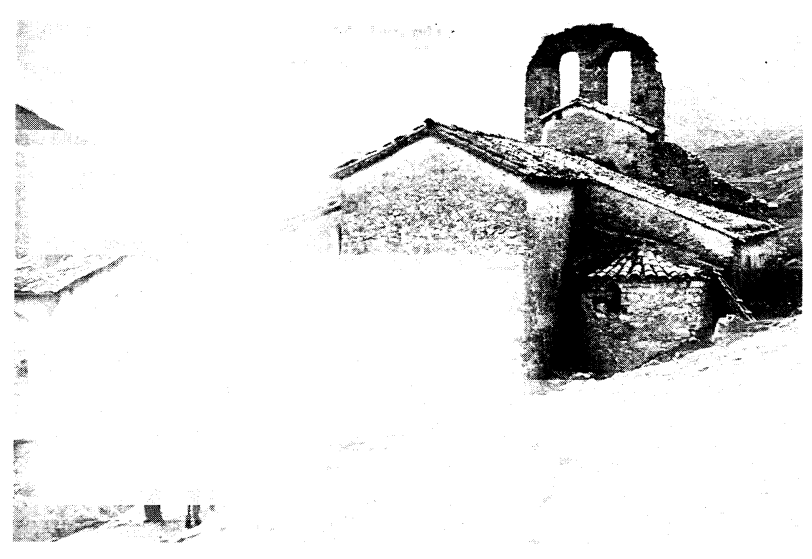

Estado del edificio a principios del siglo XX.

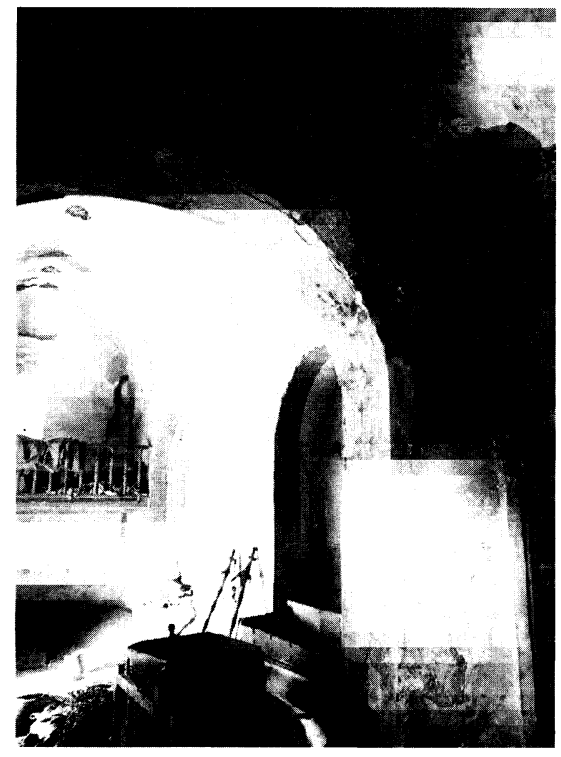

Interior de la iglesia a principios del siglo $X X$.

XVIII, se construyó la inmensa espadaña de dos ojos que coronó hasta fecha reciente el muro de poniente, a cuya base se accedía por una escalera apoyada en la nave norte.

\section{LA PRIMERA RESTAURACIÓN}

La iglesia -sin apenas culto desde finales del siglo XIX- fue cedida en 1959 por el obispado de Solsona al ayuntamiento de Berga para que, con la ayuda de la Diputación de Barcelona, la conservara. Entre 1959 y 1964 fue restaurada por el servicio de monumentos de la diputación, del que era jefe en aquel momento el arquitecto Camil Pallàs.

Unade las primeras decisiones fue programar una excavación arqueológica, hecho no muy habitual en aquella época. La dirigióRicardBatistay, lamentablemente, nofue tan extensa como hubiera sido deseable. La excavación que se realizó después, simultáneamente a las obras, a pesar de la buena disposición del constructor Modest Buchaca (que hizo un interesante diario de los trabajos), no sedesarrolló con el rigor metodológico que hoy se exige. A pesar de sus limitaciones, estos trabajos permitieron a Camil Pallàs hacer la acertada interpretación de la evolución de Sant Quirze.

Por la importancia y singularidad en Cataluña de un edificio de aquella época, Pallàs propuso la recuperación, a grandes rasgos, de las trazas del edificio en el siglo X. Ese planteamiento obligó a una actuación contundente sobre la fábrica, que tuvo su lado positivo, al permitir profundizar en el conocimiento dè su historia, ya que aparecieron elementos originales (ventanas, enlucidos, huellas de la cubierta, etc.) hasta entonces desconocidos. Se desmontó gran parte de la bóveda apuntada del siglo XIII, así como los muros que la sustentaban, y se rebajaron los muros exteriores 


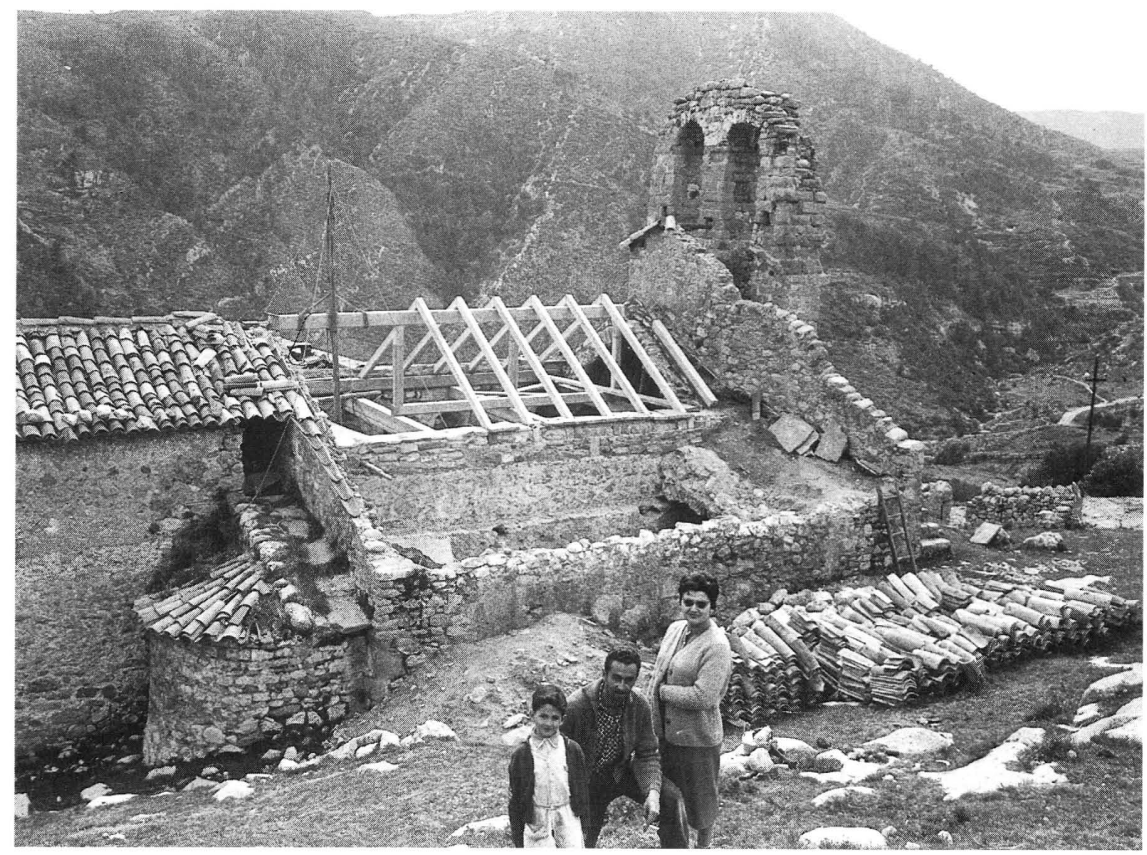

El constructor Modest Buchaca con su familia, durante el curso de la primera restauración (abril de 1960).

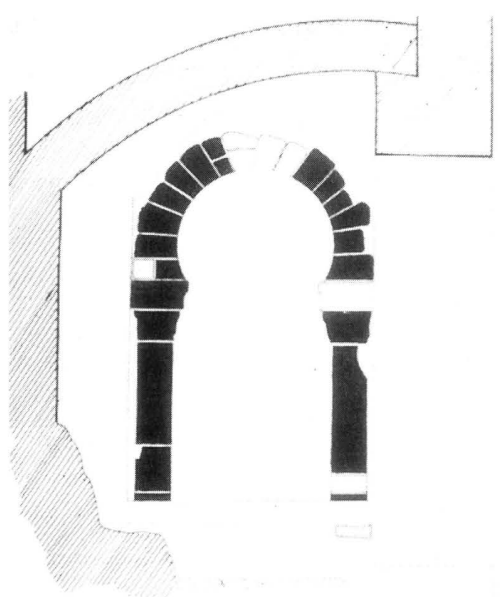

Mustración del diario del constructor Modest Buchaca.

recrecidos en el siglo XVIII. Se conservaron, sin embargo, la portada románica y la maltrecha espadaña, que no fue ni desmontada, ni restaurada.

En el proceso de recuperación formal se rehicieron dos delos arcos de herradura interiores que habían desaparecido en el siglo XIII, se restituyeron las columnas al arco del ábside sur, se construyó una cubierta de cuchillos de hormigón armado -a imitación de las antiguas de maderay se trató de ambientar el interior evocando una cierta estética alto medieval.

Un cuarto de siglo después, la fábrica de Sant Quirze padecía los efectos del envejecimiento de los materiales utilizados, la acción antrópica y natural y, en general, la falta de

(c) Consejo Superior de Investigaciones Científicas Licencia Creative Commons 3.0 España (by-nc)

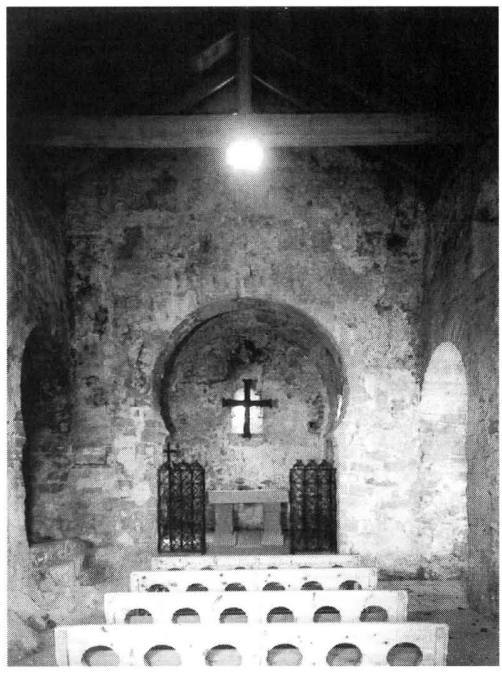

Interior de la iglesia después de la primera restauración (sept. de 1964).

¿onservación. Las cubiertas se habían deteriorado gravemente, el interior había sufrido las consecuencias de la humedad y la falta de urbanidad de algunos visitantes, y el entorno ofrecía un aspecto discordante con la importancia del monumento.

\section{LA SEGUNDA RESTAURACIÓN}

En 1988, el ayuntamiento de Berga solicitó de nuevo ayuda a la Diputación que, a través de su renovado servicio de monumentos, programó una segundacampañaderestauración. De acuerdo con el nuevo método que el servicio aplicaba desde mediados de los años ochenta ${ }^{4}$, un equipo 


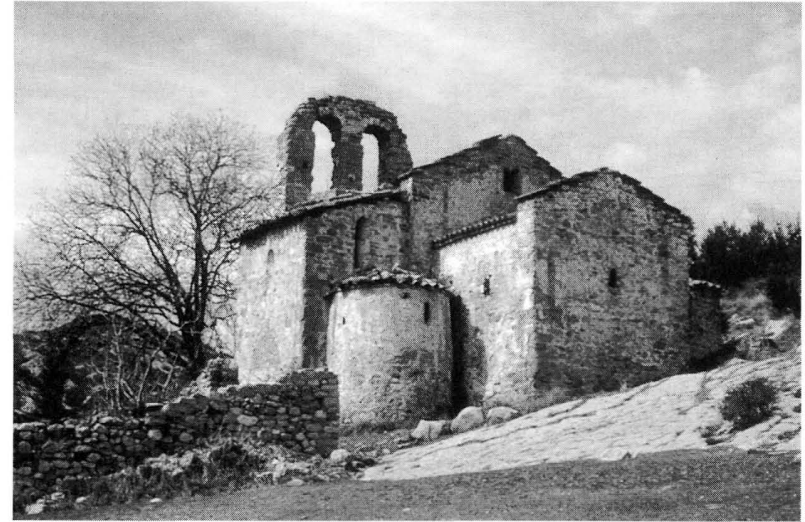

Estado del edificio en 1989, 25 años después de acabada la primera restauración.

pluridisciplinar hizo un análisis inicial de la problemática del edificio, referida no sólo a la conservación de la fábrica sino también a su accesibilidad, uso y vigilancia. Igualmente se detectó que continuaban existiendo graves lagunas en el conocimiento e interpretación de su evolución constructiva, ya que había resurgido (aunque sin fundamento científico) la teoría de una única fase inicial de tres naves.

Esta situación aconsejó que una parte esencial delos trabajos iniciales realizados en Pedret a partir de 1989 consistieran en completar la investigación arqueológica de 1960 -incluso volviendo a excavar las zonas que lo fueron entonces-, extendiendo el análisis estratigráfico a los paramentos, las

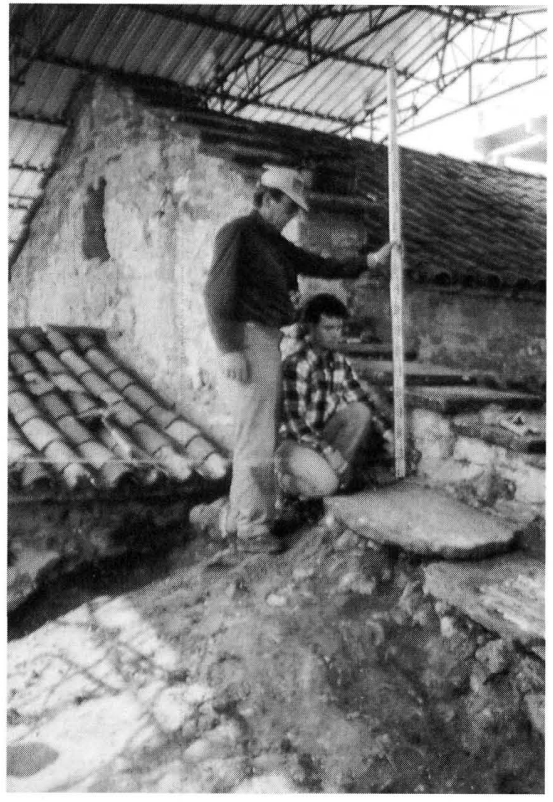

Investigación arqueológica en la cubierta del ábside norte durante los trabajos iniciales de la segunda restauración.

cubiertas y, en general, a todas las fábricas aéreas y espacios cerrados, y realizándose los consiguientes estudios concurrentes (ceramología, numismática, antropología fisica, etc.)

La excavación, aparte de datar las fases de la evolución y dar por zanjada la polémica sobre las etapas iniciales, permitió
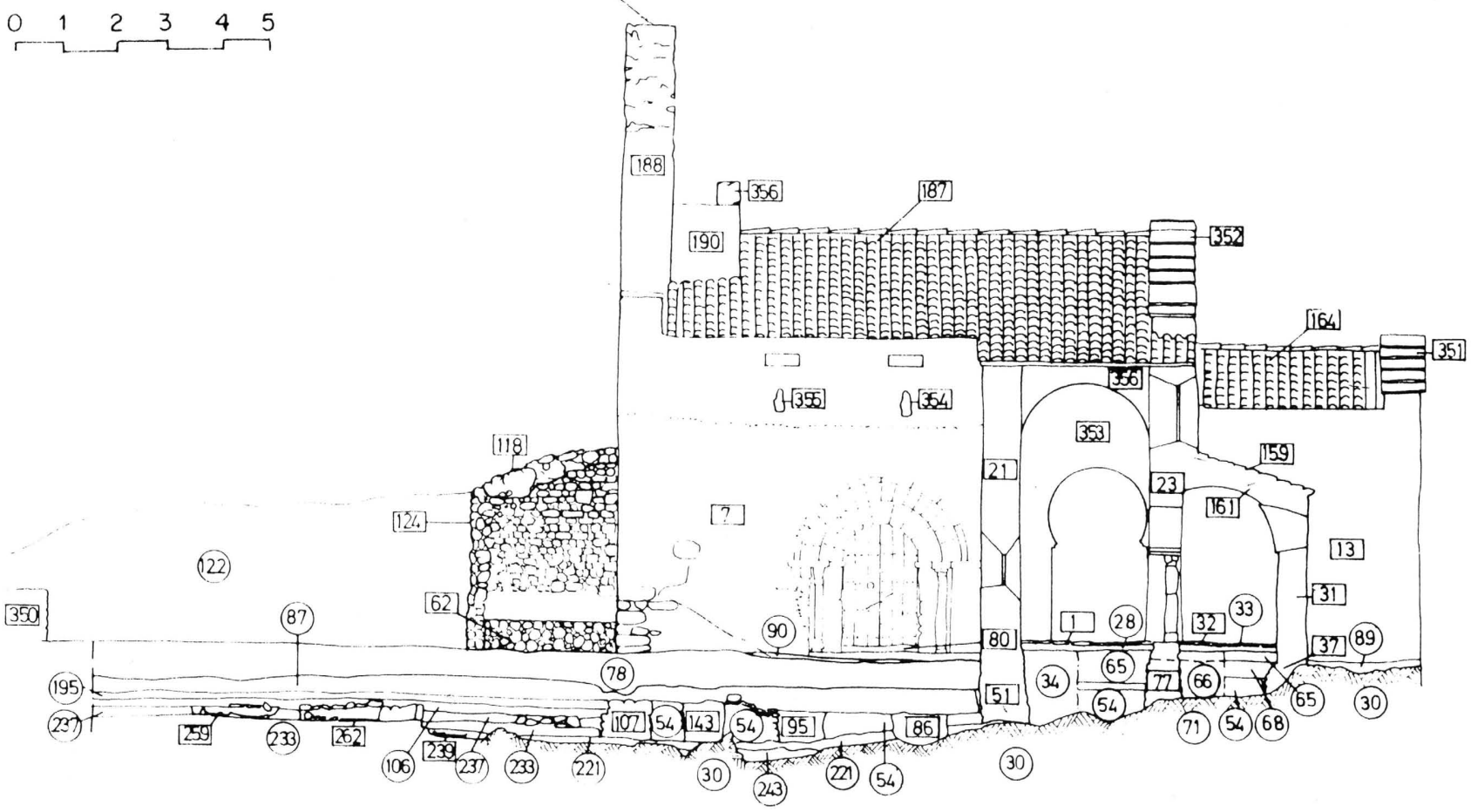

Sección de la iglesia por la nave sur (antes de la restauración) con indicación de las diversas unidades estratigráficas. 
determinar la forma y posición de la cubierta del siglo $\mathrm{X}$, estudiar el espacio funerario que durante diez siglos se formó en torno al templo y precisar la topografia del lugar a lo largo de su historia. La investigación histórica comportó también la realización de estudios de historia del arte (incluido el inventario de elementos arquitectónicos hallados en la excavación), la búsqueda dela documentación bajo medieval y moderna y los análisis histórico-constructivos ${ }^{5}$. Estos trabajos posibilitaron mejorar la información sobre la evolución deledificioy plantear las conclusiones definitivas ${ }^{6}$.

Esta primera fase de los trabajos contó también con los pertinentes estudios sobre la geometría real del edificio, los análisis fisico-constructivos -incluidos los de materiales y morteros-, los estudios ambientales, etc. (realizados por profesionales del propio Servicio o por equipos de científicos de las tres universidades públicas de Barcelona), tendentes todos ellos a la definición lo más completa posible de la realidad fisica y la problemática del monumento y de su entorno. A partir de estas informaciones pudo plantearse la segunda etapa, o "intervención” propiamente dicha, con la máxima objetividad.

\section{RESTAURAR LA ARQUITECTURA TESTIMONIAL}

En la determinación de los criterios de esta intervención, además de esas conclusiones, se tuvo en cuenta un planteamiento conceptual genérico sobre la actuación en arquitecturas cuyo interés histórico o arquitectónico hace

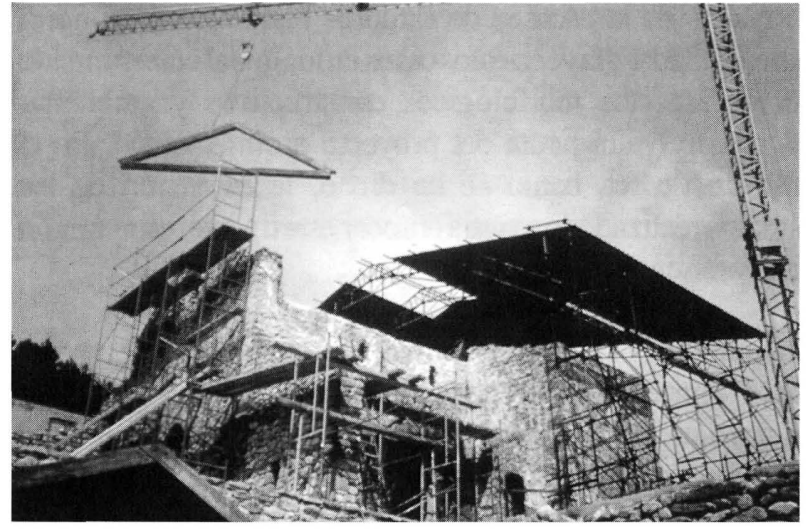

Sustitución de la cubierta de hormigón armado de 1960 por otra de madera, realizada de acuerdo con los resultados de la investigación histórica.

que el principal objetivo de su conservación sea el de testimoniar la historia y la cultura del pasado, por considerar Pedret un ejemplo paradigmático de esta "arquitectura testimonial".

Transmitir a las futuras generaciones la autenticidad de la arquitectura testimonial (como objetivo esencial de su restauración), a menudo no supone tanto conservar la materia heredada, como -en función de un objetivo didácticodescubrir y recuperar los valores genuinos (forma, textura, luz, espacio, ambiente, etc.), que han podido perderse por traumatismos históricos o terapéuticas restauradoras erróneas. En este objetivo se topa a menudo con dificultades

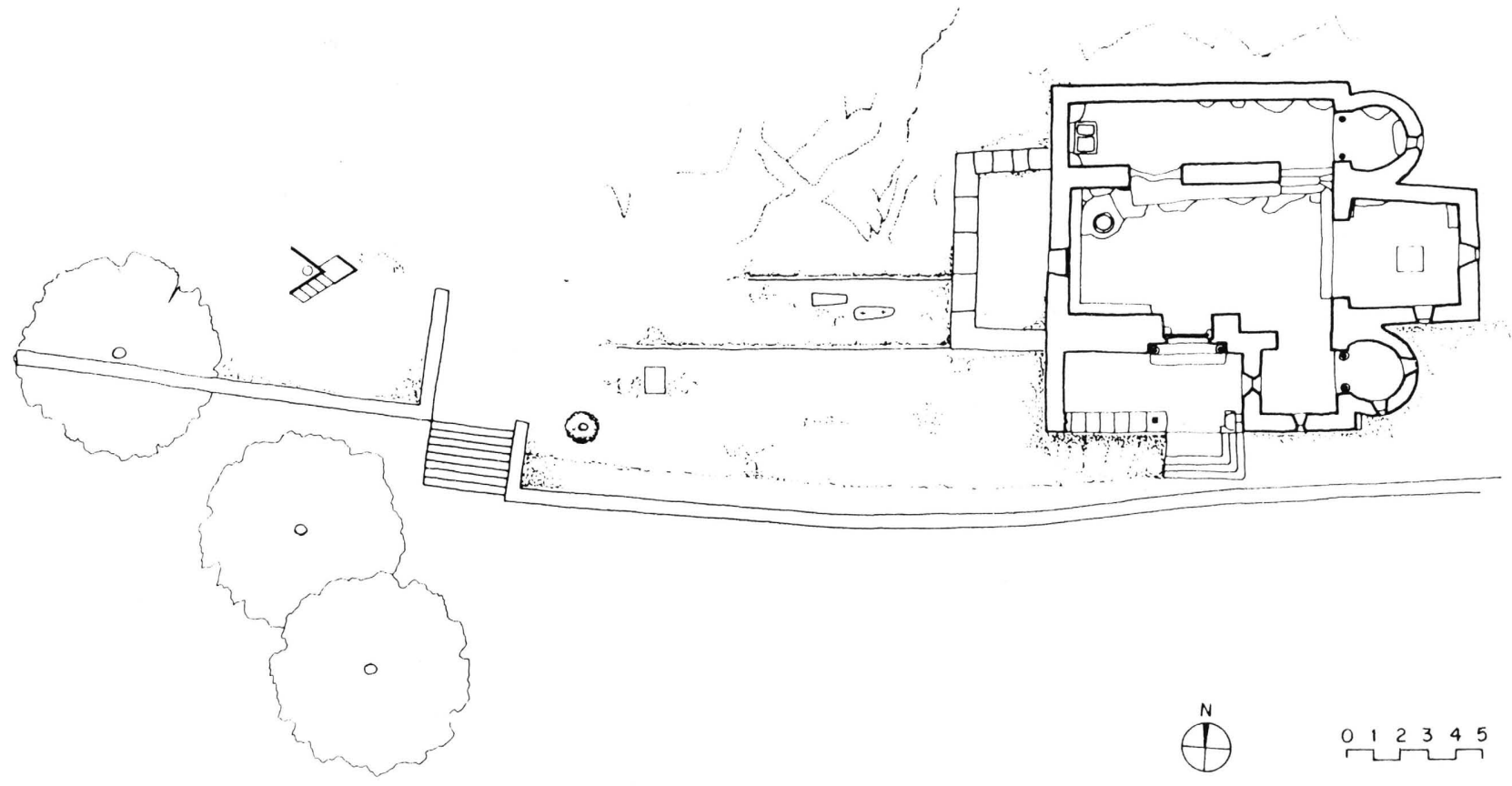

Planta general de la iglesia y el entorno después de la restauración. 
derivadas de la escasez de estudios históricos profundos, especialmente graveen estos casos enlos queel conocimiento de los aspectos morfológicos, constructivos y ambientales constituye la pauta del proyecto arquitectónico. En el caso de Pedret, como se ha dicho, la extensión de los estudios realizados permitía enfocar este tipo derestauración con garantías suficientes.

En cuanto a los criterios proyectuales aplicables en estos casos apostamos, en general -salvando la variedad de circunstancias particulares que pueden condicionar la elección-, por la reconstrucción mimética basada en datos científicos, lo que hemos llamado mimetismo científico. Un mimetismo proscrito, pero legítimo a nuestro juicio cuando el objetivo didáctico es prioritario y sólo aceptable, por supuesto, en función del rigor con el que se acometa y siempre que se aplique con prudencia cuando el monumento presente superposiciones históricas de interés ${ }^{6}$. En la iglesia de Sant Quirze de Pedret, por esa condición ya citada de ser obra capital de la arquitectura prerrománica y uno de los pocos edificios del siglo X que quedan en Cataluña, la intervención seplanteó como continuación dela restauración de los años sesenta, es decir, basada en la recuperación de la apariencia que debía de tener el edificio en aquel siglo.

\section{LA ACTUACIÓN EN EL EXTERIOR DEL EDIFICIO}

Ese objetivo prioritario, no obstante, tanto ahora como en la primera restauración, no había de comportar la eliminación de algunas aportaciones interesantes de la época románica (especialmente la portada y los restos del campanario de torre). En cuanto a la espadaña del siglo XVIII -en base a su valoración como punto de referencia paisajístico y sentimental- se pensó, en un principio, en conservarla una vez restaurada. Sin embargo, su mal estado de conservación y la grave alteración que producía de la imagen del edificio prerrománico que se trataba de restablecer, nos movieron a desmontarla en 1990

Las piedras de la espadaña fueron utilizadas en la construcción del porche que se alzó a mediodía, un espacio con vocación de convertirse en punto de referencia alternativo, un lugar de reposo, encuentro y comunicación. La creación de este porche, no obstante, tuvo otra intención primordial: devolver a la iglesia su traza del siglo X, por lo que su planta se hizo coincidir con la de la parte de la nave sur que se desplomó en el siglo XIII. El muro de poniente de la desaparecida nave se rehizo entero (con piedras del lugar, trabajadas como se hacía en la época prerrománica, y mortero de cal), de modo que la fachada oeste de la iglesia vuelve a ser como en el siglo $X$, con lo que una visión frontal olejana del templo sugiere con claridad su tipología de tres naves.

El pórtico permite además que el acceso a la nave central (al interior de la iglesia actual) no se produzca de forma directa, sino según una secuencia gradual. El nuevo pórtico, por otra parte, permite la protección de la portada románica, que queda ahora fuera del alcance de la lluvia portadora de los agentes que han causado su degradación. La restauración de la portada, debido al avanzado estado de deterioro de la piedra, seplanteó únicamentecomo limpiezay consolidación, sin reintegrar la materia perdida. Se limpió primero con procedimientos físicos, eliminando la vegetación con inyección de formol y las juntas se sellaron con mortero de cal. Unos meses después de ser consolidada, se procedió a la hidrofugación.

También quisimos devolver a los muros sus texturas originales, que en nuestra opinión nunca fueron las de la piedra a la vista. Las fotografias del siglo XIX ya nos ilustran del "Pedret blanco". Pero, además, en el curso de la obra encontramos infinidad de evidencias de que aquellos muros estuvieron siempre revestidos de mortero y cal. Pretendimos conservar lamayor partedelos revestimientos existentes, completando las lagunas con otros nuevos, también de cal. Las pruebas para el endurecimiento y envejecimiento de los nuevos, a base de Paraloid B72 al 5\% y Tegovacon V., no dieron buen resultado. Tampoco nos convenció el esfuerzo quehabía que hacer-y la poca garantía deéxito- para consolidar los morteros antiguos con productos sintéticos, por lo que se decidió finalmente conservar únicamente los que se mantenían bien adheridos.

El retorno formal al siglo X obligó a algunas alteraciones de los muros, tanto los de soporte de las estructuras como los hastiales. Después de replantear las pendientes delas cubiertas (que fue uno de los trabajos más arduos de la obra), en los muros longitudinales hubo que eliminar algunos añadidos modernos. Al variar la altura y pendientes delos hastiales, los coronamientos que dispuso el arquitecto Pallàs en la primera restauración tuvieron que ser desmontados y vueltos a colocar.

En el curso de la intervención en los muros se reabrió la ventana prerrománica de la fachada oeste -cerrada desde el siglo XIII- $y$, en la fachada opuesta, se rehizo el pequeño ajimez. La mayor parte de las aberturas se cerraron con alabastro y algunas con rejilla inoxidable para favorecer la ventilación y evitar la condensación. En la gran abertura de poniente, el alabastro -dividido en cuatro piezas, que dejan entre ellas un rombo por el que es posible otear el interiorse halla protegido entre dos vidrios de alta resistencia.

Otra acción esencial de recuperación afectó a la cubierta. La estructura de hormigón armado que en 1960 sustituyó a la bóveda de la nave central, fue desmontada y enterrada en un lugar próximo a la iglesia (por respeto hacia quienes la hicieron y por considerar que más adelante puede tener interés científico analizarla). La iglesia se cubre ahora como en el siglo X: en la nave central, a base de cuchillos simples de par y tirante sin pendolón; en la nave norte, el porche y el campanariode torre, con vigas simples deescuadría cuadrada. Toda la estructura se realizó con madera de pino melis, 


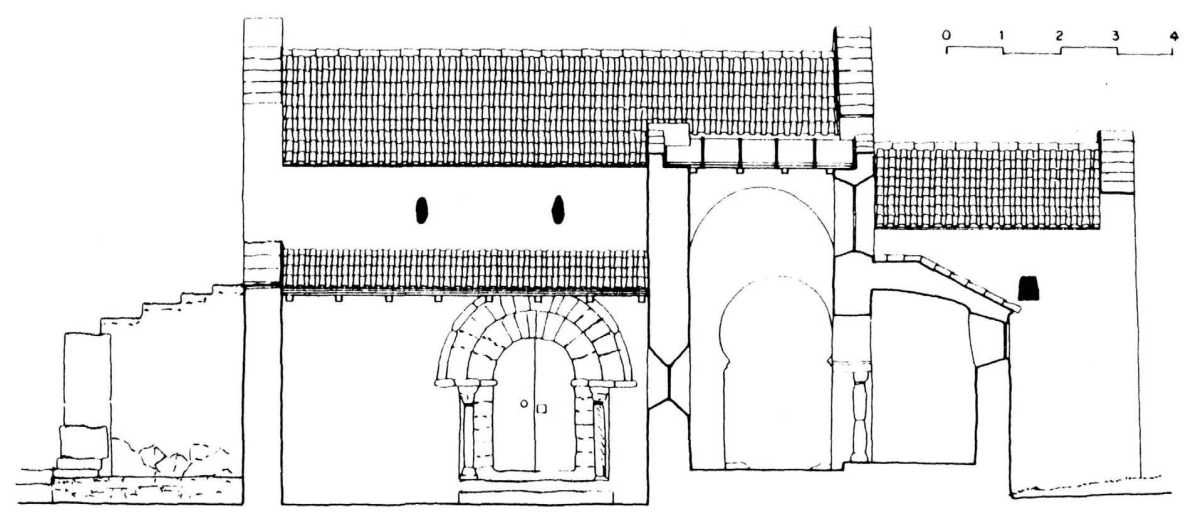

Sección de la iglesia por la nave sur, después de la restauración.

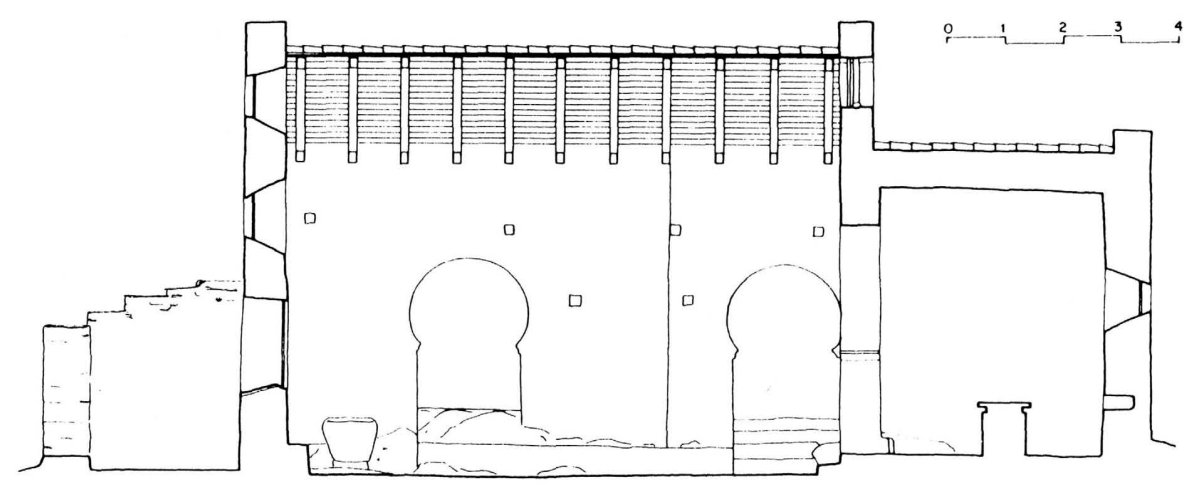

Sección longitudinal con vistas hacia el norte.

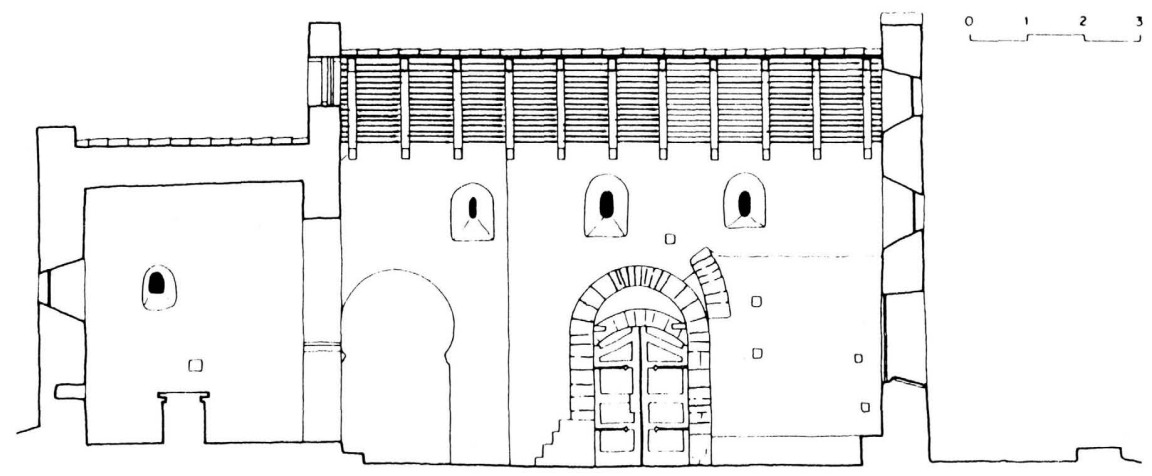

Sección longitudinal con vistas hacia el sur. 


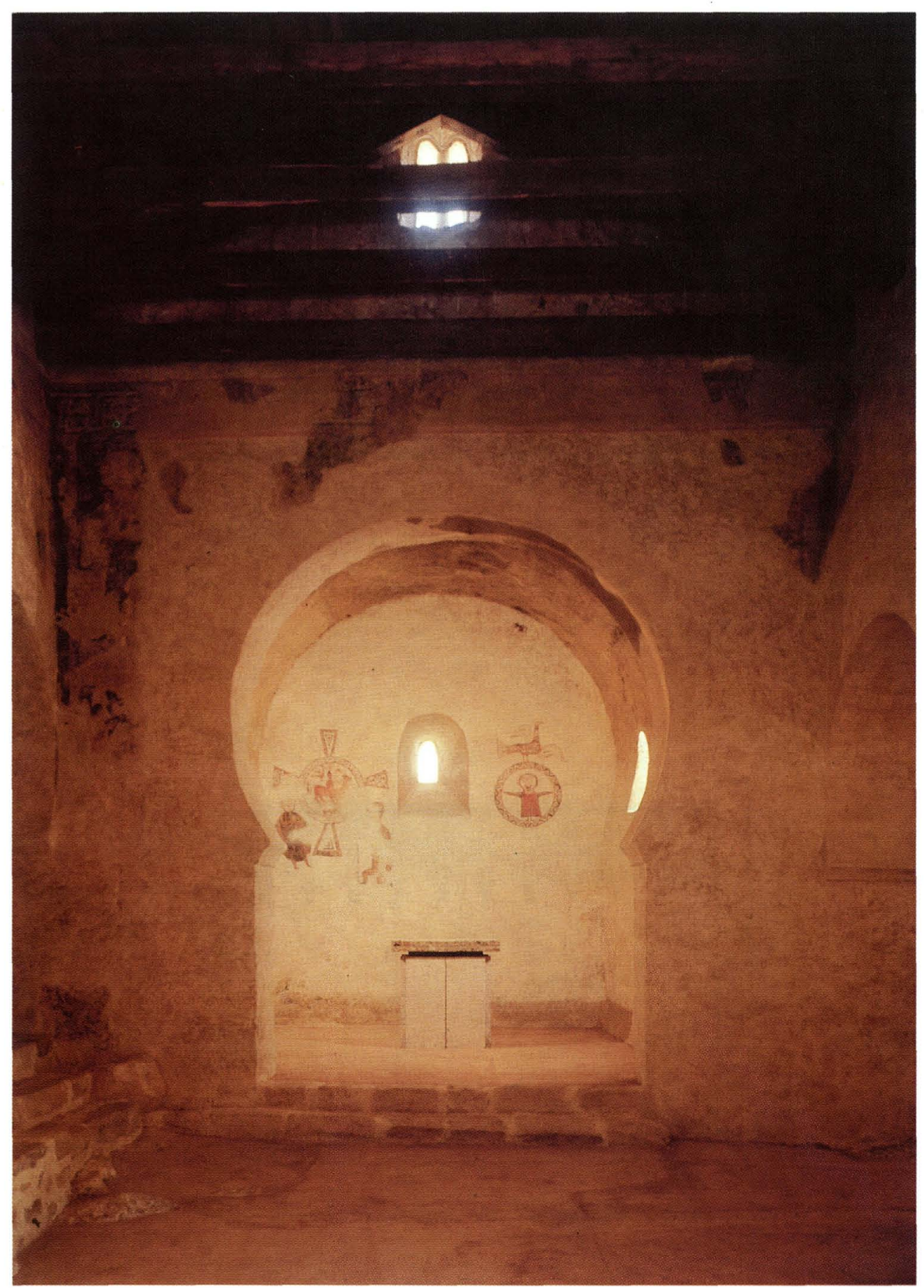

La nave central después de la restauración (19 de octubre de 1995).

procedente de una antigua fábrica textil del siglo XIX. El envejecimiento que presenta el material es, por lo tanto, natural.

Sobre la tablazón de las naves central y norte se colocó un aislante de placas de poliestireno extrusionado de 250 x $600 \mathrm{~cm}$ y $30 \mathrm{~mm}$ de grueso, una tela de PVC y una capa de compresión de $4-5 \mathrm{~cm}$ con mallazo metálico. Sobre esta capa se dispusieron tejas árabes por haber demostrado la arqueología que habían sido así las cubiertas originales, y no de pizarra como se pensó inicialmente. Las tejas de las naves y del porche proceden de antiguas construcciones del medionural. Lasdelosábsidesfueronfabricadas expresamente siguiendo el modelo de los restos de una teja del siglo $\mathrm{X}$ que se encontró en su ubicación original durante la excavación. Son de menor tamaño que las de las naves, lo que facilita su imbricación. Las bases de los tejados de los ábsides se hicieron con mortero de cal (ligeramente enriquecido con cemento blanco) y ladrillo triturado, para consèguir una hidrofugación suficiente. Lacubierta de la torre-campanario, que antes montaba sobre los muros vèrtiendo sobre éstos las aguas pluviales, se sustituyó por una de planchas de cobre cercada por los muros perimetrales rematados de forma irregular, para sugerir las dudas sobre si realmente el campanario llegó a completarse.

\section{LA ACTUACIÓN'EN EL INTERIOR}

El objetivo esencial de la actuación en el interior fue también la recuperación lo más fiel posible de la imagen y el ambiente del siglo X. Con esefin se procedió ala eliminación de algunos 

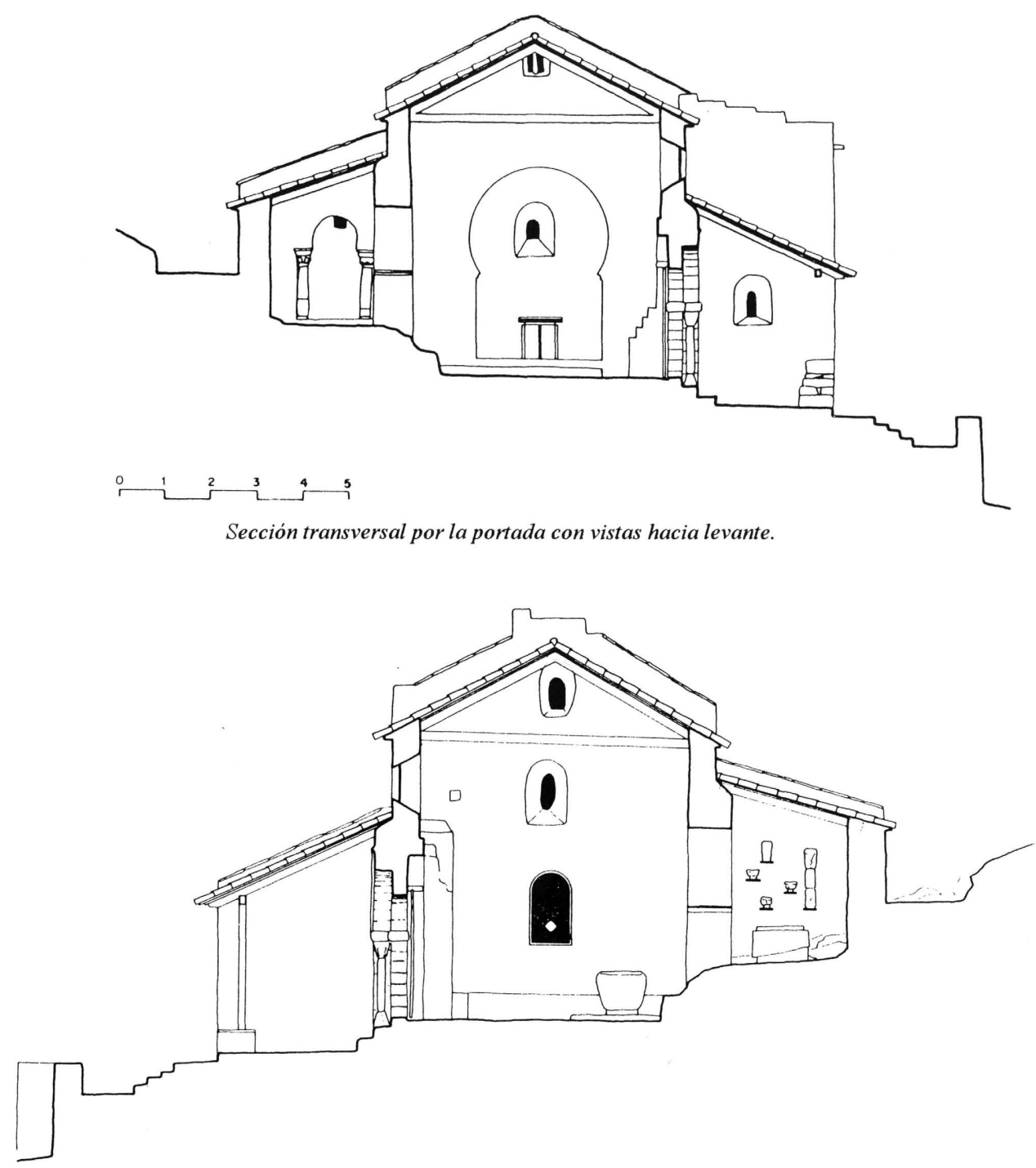

Sección transversal por la portada con vistas hacia poniente.

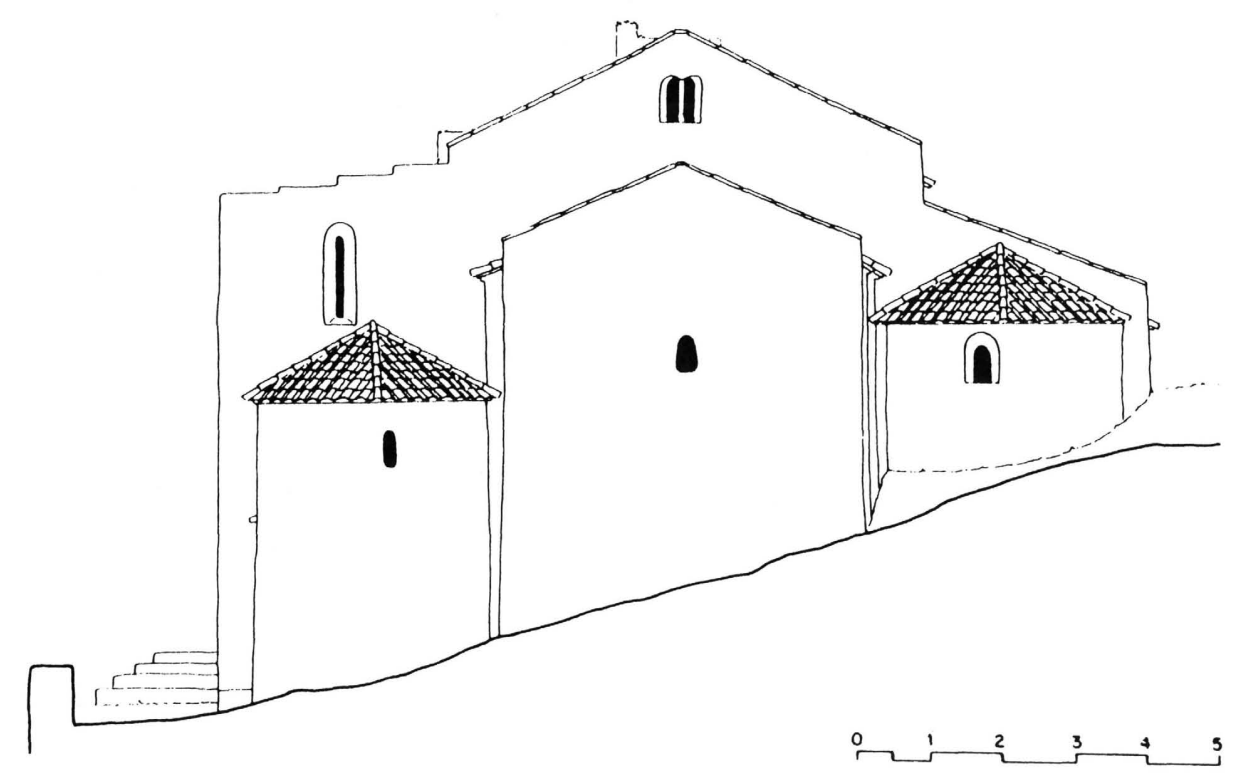

Fachada de levante después de la restauración. 


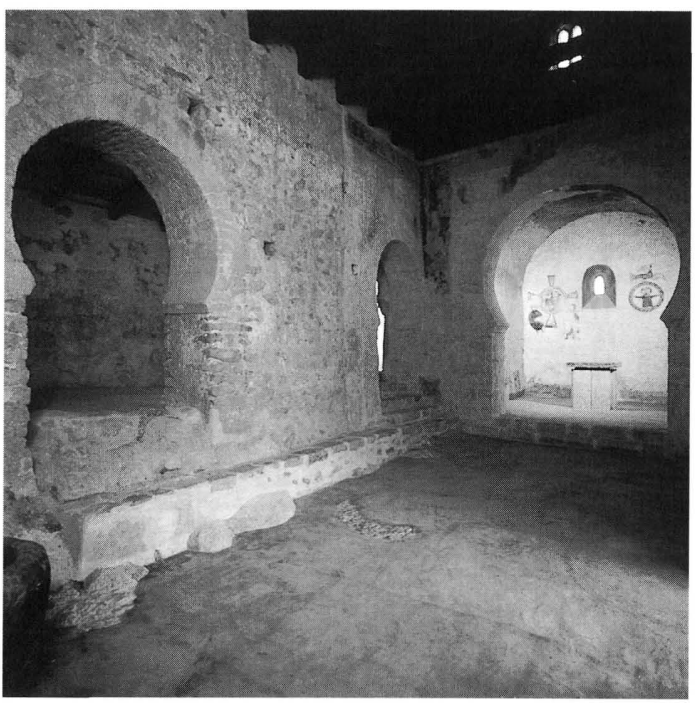

Nave central, vista hacia levante (19 de octubre de 1995).

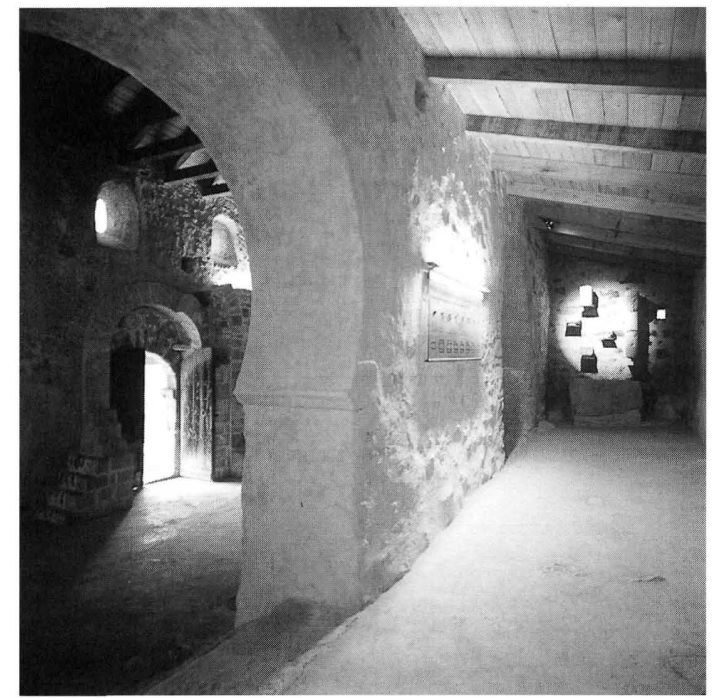

Nave norte, vista hacia poniente (21 de febrero de 1996).

restos más modernosque subsistieron alaprimera restauración. Estos desmontajes fueron aprovechados para reconocer la fábrica (comprobar la existencia de más pinturas murales, establecer relaciones entre muros, etc.). Todos estos elementos desmontados fueron documentados previamente, fotográfica y gráficamente, documentos que pasaron a formar parte del Atlas constructivo del monumento.

En el fragmento de muro del siglo XIII contiguo a la jamba interior de la portada, que se conservó, se practicó una exploración para descartar la posibilidad de que tras él se escondiera el cuarto arco de herradura del que nunca se hallaron rastros ( $\sin$ duda, por coincidir con la abertura de la puerta actual, hipótesis reafirmada con esa indagación). La jamba contraria, desmontada en 1960, se ha rehecho parcialmente para una mejor comprensión de la relación constructiva de la portada y el muro interior.

Adosados a los paramentos norte y oeste de la nave se (c) Consejo Superior de Investigaciones Científicas Licencia Creative Commons 3.0 España (by-nc)

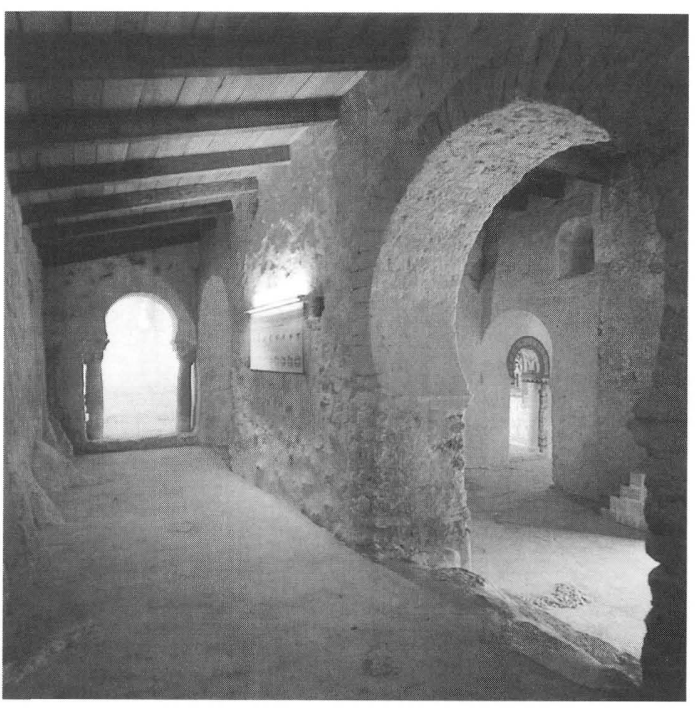

Nave norte, vista hacia levante (21 de febrero de 1996).

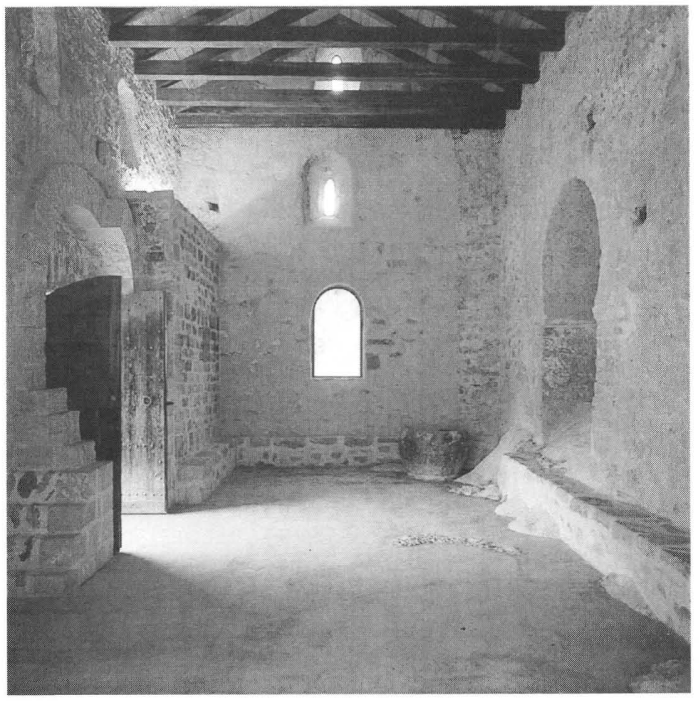

Nave central, vista hacia poniente (19 de octubre de 1996).

rehicieron los bancos perimetrales del siglo $\mathrm{X}$ y en el rincón noroeste se situó la pila bautismal románica, que se halló en el exterior, pero que ocupó en su día aquel sector de la nave. $\mathrm{El}$ arco de herradura entre las naves sur y central, hecho de nueva planta en 1960 , se conservó por su calidad y fidelidad histórica. Sin embargo, las escaleras de comunicación entre las naves central y norte, se desmontaron y se rehicieron siguiendo la información fotográfica antigua.

Otra de las mejoras de la obra realizada en los años sesenta fue la rectificación del arco de herradura del presbiterio o ábside mayor. Camil Pallàs encontró aquel arco (que, según parece, se mantuvo igual desde el siglo IX al XIII) tal como quedó transformado en este último siglo, sin impostas y con lasjambas modificadas, es decir, habiendoperdido su primitiva forma de herradura. Tratando de recuperar su perfil original, se colocaron entonces dos impostas, aunque a distinto nivel, y se avanzó una de las jambas, no haciéndose lo mismo con 


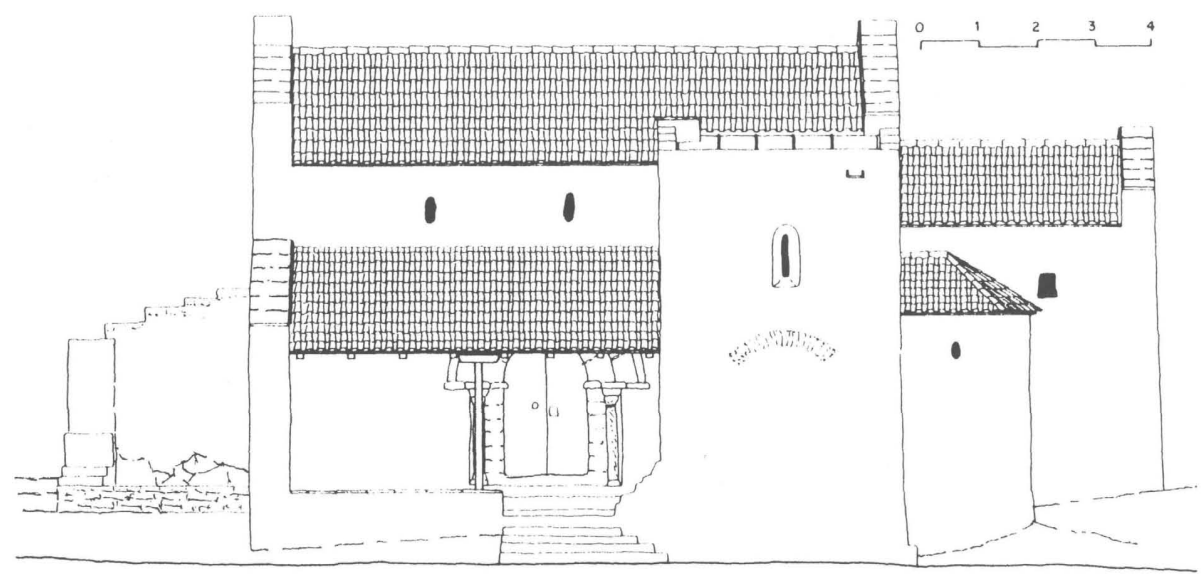

Fachada de mediodia después de la restauración.
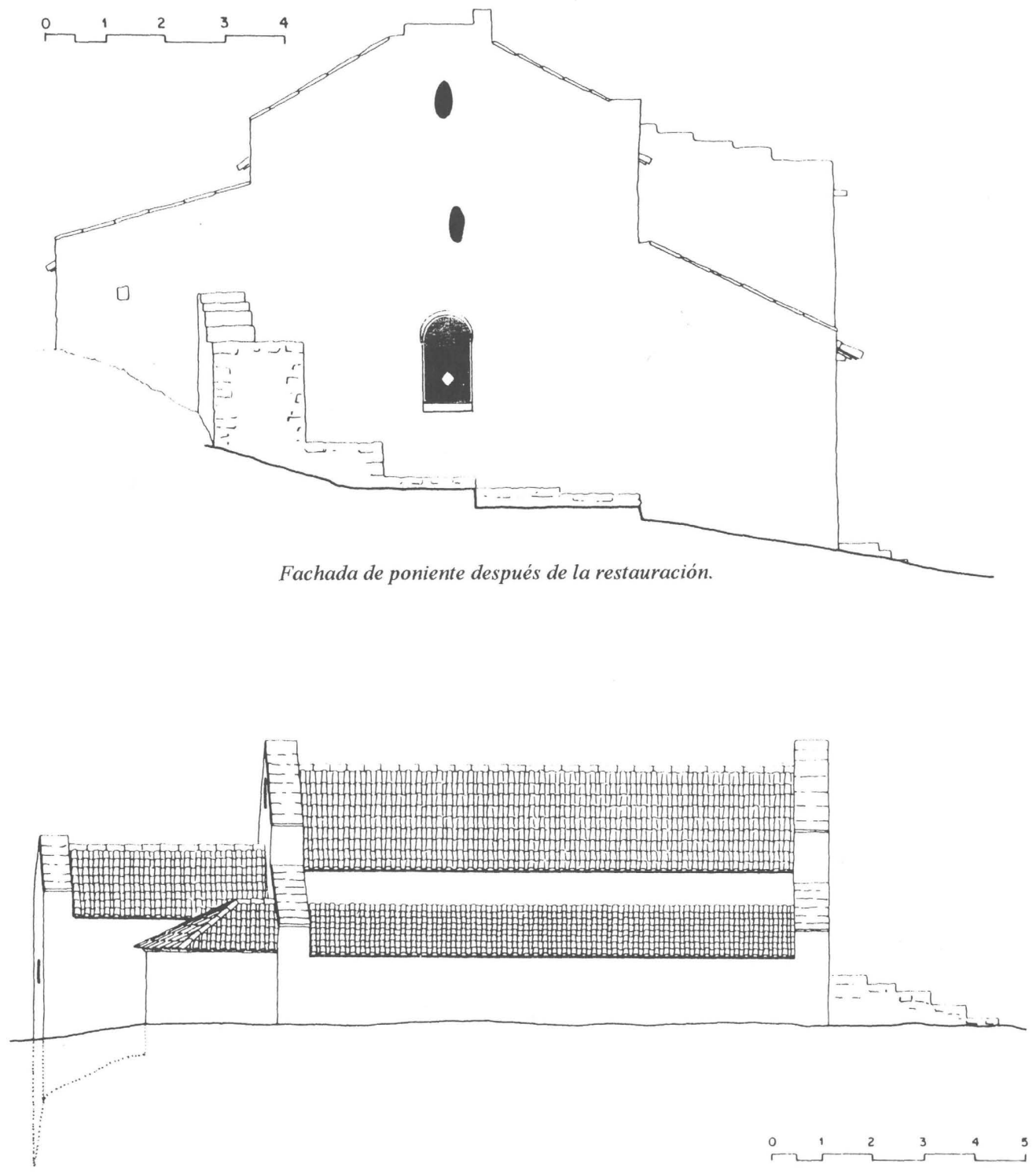

Fachada de tramontana después de la restauración. 


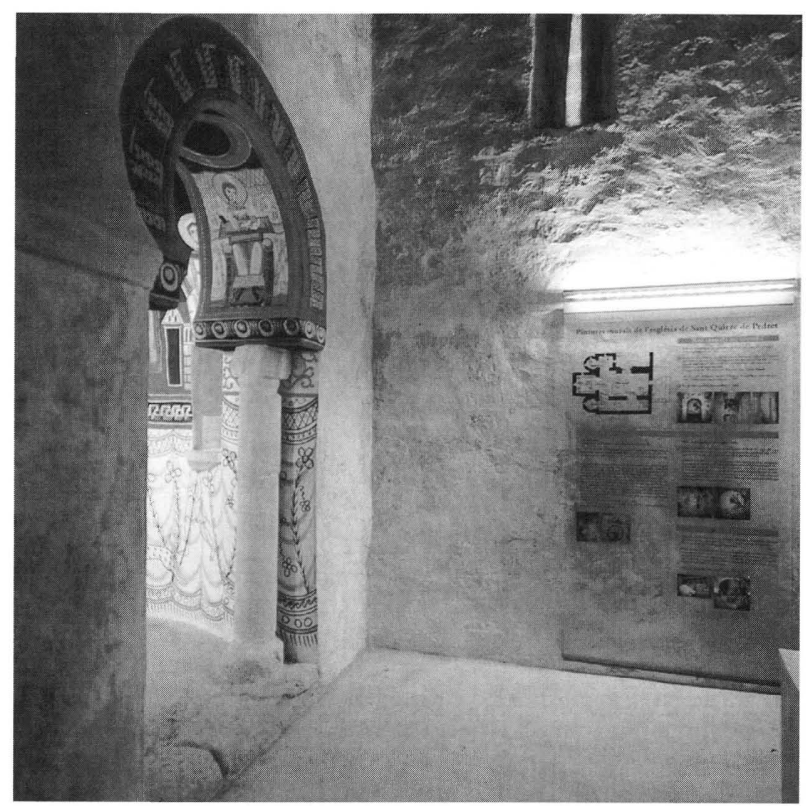

Entrada al ábside sur que contiene las pinturas románicas reproducidas (21 de febrero de 1996).

la otra. Analizado con detenimiento el arco pudimos deducir que, originalmente, había sido del mismo tipo y proporciones que los arcos de comunicación entre las naves, con una relación de 1:1,5. Se dibujó con precisión el perfil y, para reconstruirlo, desplazamos las impostas de 1960 y avanzamos la jamba que entonces no se movió.

En este ábside mayor, al finalizar la primera restauración, Camil Pallàs colocó un altar de piedra sobre dos pares de columnas geminadas de gusto prerrománico. Sobre el ara, colgada de la bóveda, suspendió una cruz metálica y cerró el espacio con una reja, también metálica. Todos estos elementos fueron desmontados en 1989. Durante los trabajos arqueológicos posteriores se hallaron los cimientos de la base del primitivo altar prerrománico, pero no se pudo extraer conclusiones que permitieran deducir el funcionamiento exacto de aquel espacio presbiteral. Seoptó, por lo tanto, por situar en el mismo lugar que ocupó el altar primitivo el nuevo altar y diseñar éste con voluntad de aparente intemporalidad.

El pavimento de las naves y los ábsides ha recobrado la apariencia de tierra batida con cal que tenía el del siglo X. El nuevo pavimento se hizo según la técnica antigua de opus signinum, a base de cal y ladrillo manual triturado, con armazón interior de malla de plástico para evitar fisuras. La superficie fue limpiada con salfumán y repasada con aceite de linaza y ceras. La base de hormigón se hizo con cemento especial compatible con los sulfuros, el I/35A/SR-MR (UNE 80.301/88), ya que las sales de un cemento portland ordinario podía dañar los muros y las pinturas. La base no es continua ni de sección uniforme. En algunos puntos la roca virgen emerge del pavimento, lo que en un principio creímos

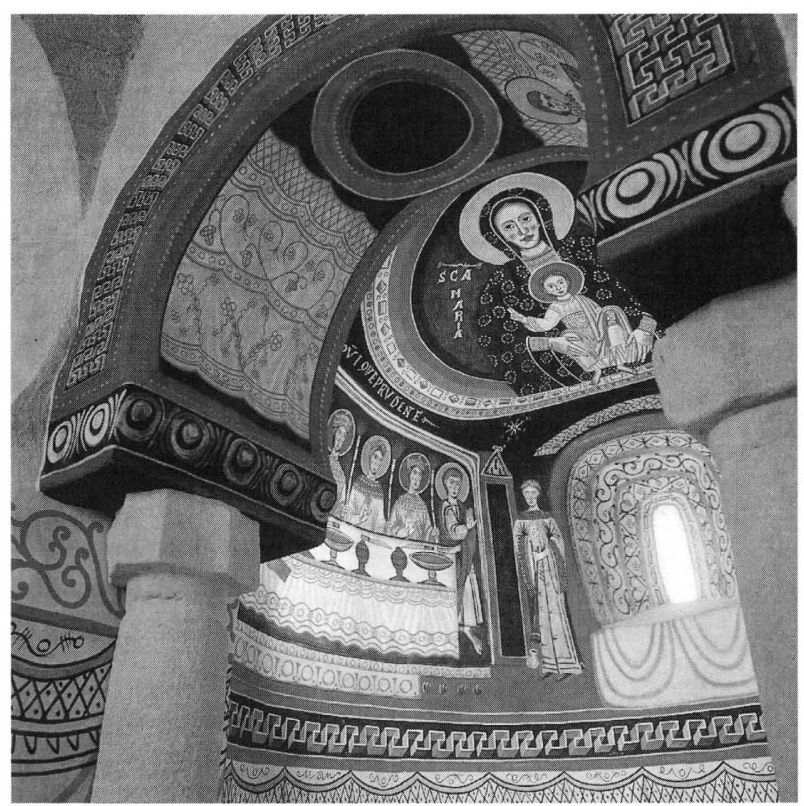

Detalle de las pinturas del ábside sur (2 de octubre de 1995).

que sería suficiente para permitir que el suelo continuara transpirando.

\section{LARECUPERACIÓNDELASPINTURASMURALES}

Recuperar las texturas originales de los muros era también un objetivo irrenunciable de nuestra actuación. En la mayor parte de la superficie de las naves se tuvo únicamente que limpiar y consolidar los morteros, casi todos originales, ya que aparecieron al desmontar en 1960 los muros que sustentabanla bóveday que, por lo tanto, habían sido sellados por ellos en el siglo XIII. La cabecera y la zona de la nave central próxima, que habían sido revestidas con pinturas en el siglo XI, recibieron un tratamiento especial para lograr una textura más homogénea. Se enlucieron todas las superficies con una mezcla de plaste comercial y arena de mármol (y en algunos casos colorantes minerales naturales), diluido con $10 \%$ de agua, preservando los revestimientos originales que se conservaban en buen estado, algunos de los cuales conservan grafitos y un grafismo en forma de cruz que se asocia con la consagración de la iglesia.

Respecto a las pinturas murales, su rescate constituía, no sólo una reivindicación popular, sino un factor esencial dela recuperación de la autenticidad ambiental que se deseaba. Lógicamente no se podía pensar en trasladar desde los museos las pinturas allí depositadas, pero sí reproducirlas. El reconocimiento detallado de los muros que se realizó previamente a la reproducción demostró que aún se conservaban en su lugar una buena cantidad defragmentos de pintura original. 
Nuestra intervención, finalmente, se basó en tres criterios, según el caso. Por una parte, se procedió a restaurar los restos de pinturas románicas que sehallaban en la nave norte y en las paredes de tramontana y mediodía del ábside central. Durante esta operación los muros fueron cuidadosamente consolidados y las lagunas pétreas mayores rellenadas con poliuretano expandido proyectado con aerosol. Por su parte, las pinturas que permanecían in situ en el paramento de la nave del muro del arco triunfal fueron arrancadas, por el temor a que se dañaran al cambiar la cubierta y más tarde fueron devueltas a su lugar una vez restauradas.

En cuanto a las pinturas prerrománicas del siglo $X$, se han reproducido en su lugar primitivo con materiales y técnicas originales. El Orant vuelve así a presidir la iglesia. Por último, con una voluntad explícitamente didáctica, se llevó a cabo la reconstrucción pictórica integral del ábside sur. Se reprodujeron las pinturas románicas conservadas en Barcelona y se completaron los fragmentos que ya faltaban cuando fueron arrancadas aquéllas, de acuerdo con un estudio de paralelos pictóricos e iconográficos. Todas estas reproducciones se hicieron con pintura al temple con colores minerales sobre fondo de pasta de cal sobre mortero también de cal. En el caso del ábside sur, fueron aplicadas sobre una piel de fibra de vidrio que preserva la base de las pinturas originales, en la que, aunque en muy mal estado, se conservaban algunas huellas y fragmentos.

Para explicar el proceso dela restauración y reproducción de estas pinturas y también para informar al visitante sobre la historia del templo, se llevó a cabo una museización del espacio interior, centrada en dos ámbitos, la nave norte y la sur. En el muro de poniente de la nave septentrional se muestran diferentes elementos pétreos (capiteles y columnas), probablemente de las épocas prerrománica y románica, sobre repisas de hierro oxidado; en el muro sur, un panel rectangular de doble vidrio serigrafiado, sostenido por una estructura de hierro oxidado e iluminado por una lámpara lineal de múltiples bombillas, muestra la evolución constructiva del templo entre los siglos IX y XX, a base de plantas y perspectivas. En la nave sur, un panel de las mismas características explica el contenido pictórico actual del templo, identificando qué pinturas han sido restauradas, reproducidas o reconstruidas, así como la localización actual de las originales.

La iluminación general del interior se resolvió con focos halógenos situados en los ábsides y las citadas lámparas lineales que iluminan los paneles e indirectamente los espacios. Una de éstas, colocada sobre los restos del muro del siglo XIII, permite una tenue iluminación dela estructura de la nave central. También se dispusieron diversas tomas de electricidad y sonido en el ábside mayor, la nave central y el pórtico. En un antiguo armario empotrado, frente al ábside sur, se instalaron los mecanismos de mando y sistemas de seguridad, el control remoto automático del nuevo campanario y las tomas para amplificación de sonido.

\section{LA RESTAURACIÓN DEL ENTORNO}

De acuerdo con el planteamiento habitual de nuestras intervenciones, la recuperación históricay la mejorafuncional de Sant Quirze de Pedret no se podía limitar al propio edificio. En el entorno se plantearon como objetivos prioritarios, la recuperación con la máxima fidelidad posible de la topografía y los accesos medievales y la adecuación del recinto para una vigilancia eficazy una correcta atención a los visitantes.

Se rehizo la parte superior del muro de contención del siglo $\mathrm{X}$ que se extiende en sentido este-oeste a pocos metros del templo, muro que fue coronado con las losas de piedra arenisca con las que en los años sesenta se había pavimentado la nave central de la iglesia, otras de las cuales constituyen ahora el pavimento del porche de mediodía. También se rehizo la plataforma queexistía en el siglo X ante esa fachada -desde la que se accede al templo por las escaleras originales aparecidas en la excavación, que fueron consolidadas sin ser desmontadas- y también las terrazas que se extendían frente a la fachada de poniente, donde se situaron las laudas sepulcrales de dos tumbas medievales aparecidas en aquel sector. La mayor parte de las sepulturas encontradas, sin embargo, permanecen ocultas por motivos de seguridad.

Junto a las fachadas norte y oeste se ha dejado a la vista el pedregal ("pedret") aparecido en la excavación, por su capacidad documental -ya que justifica el topónimo- pero también por su belleza y por dificultar la accesibilidad a la cubierta, situada a muy poca altura en la fachada norte. A lo largo de esta fachada se dispuso un drenaje de tubo y gravas para reducir la cantidad de agua que, inevitablemente, pene-

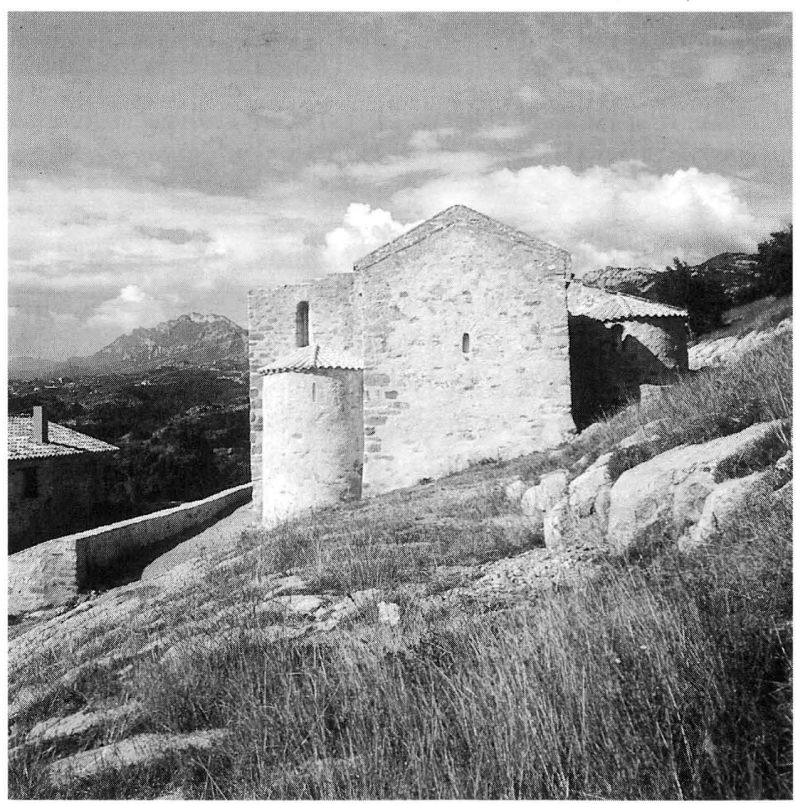

Vista de la iglesia desde levante, después de la restauración (21 de febrero de 1996). 
Informes de la Construcción. Vol. 48 n 445, septiembre/octubre 1996

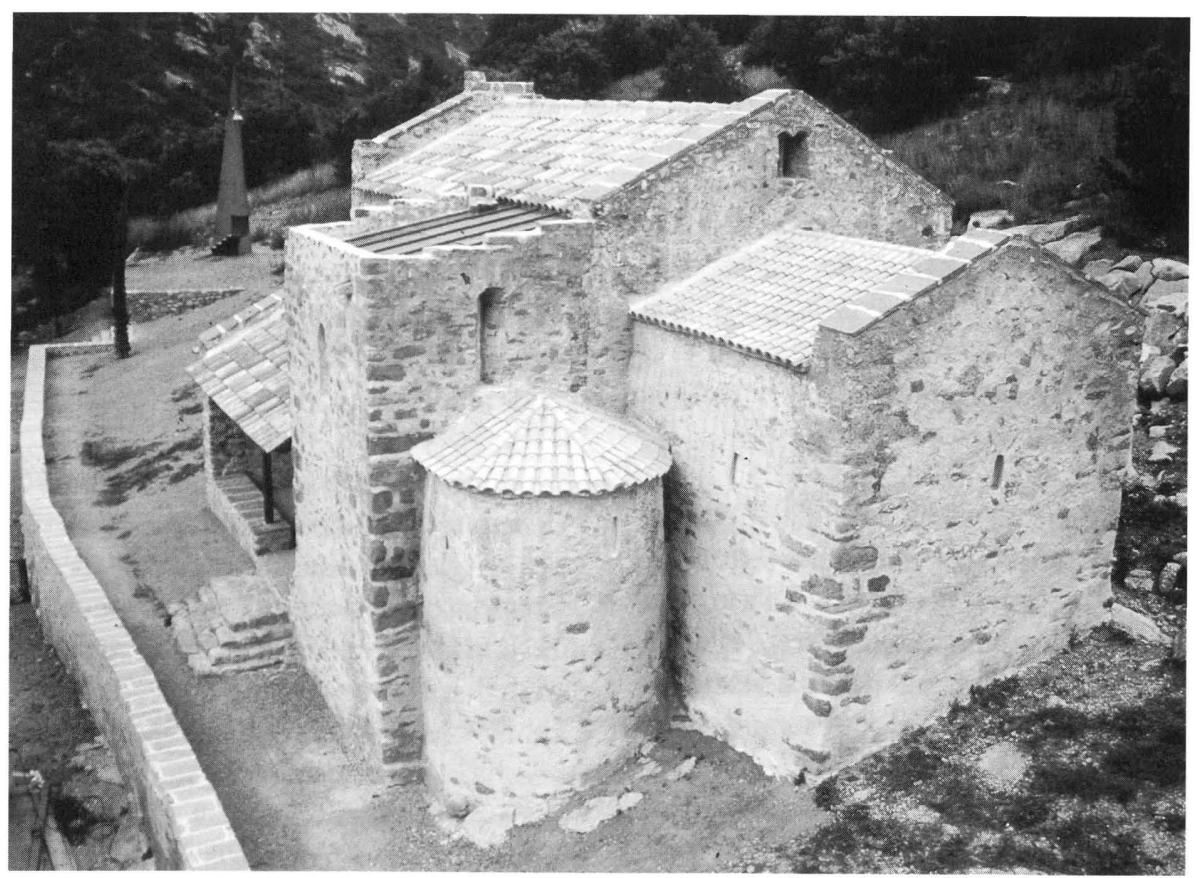

La iglesia vista desde el sudeste. Al fondo, el nuevo campanario (7 de septiembre de 1995).

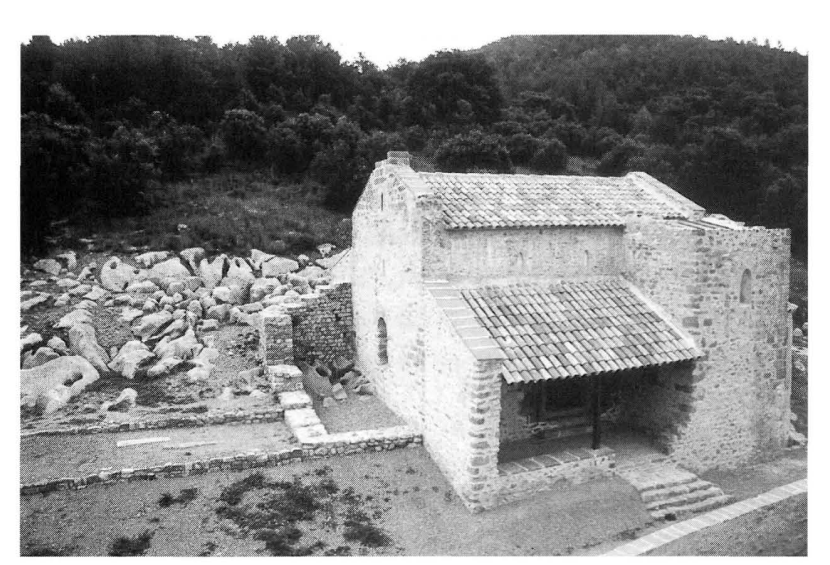

La iglesia vista desde el sudoeste. Al fondo, el pedregal origen del topónimo del lugar (21 de febrero de 1996).

tra en el edificio desde hace mil años, procedente de la ladera contigua.

El terreno colindante a la fachada de levante conserva el aspecto que tenía antes de las obras, con la roca vista inclinada lamiendo los ábsides escalonados. Junto a la fachada de poniente se han conservado y consolidado los restos del siglo XI que pertenecieron a una dependencia monacal o a un porche de acceso cuando aún existía una puerta en ese punto. En la casa vecina, edificada hace unos siglos sobre los restos del monasterio del siglo XI, se ha excavado el interior y se han consolidado y protegido los restos de los muros medievales.

En un rincón del nuevo recinto exterior, hacia el oeste, se ha formado un pequeño espacio funerario, al que fueron retornados los restos de los difuntos de la antigua parroquia de Pedret, exhumados y analizados científicamente con motivo dela excavación arqueológica. Un ciprés y una lápida de mármol verde de Brasil con inscripción dan fe de su presencia y atestiguan a los familiares y vecinos el respeto que a sus antepasados profesamos quienes, al intervenir en aquel lugar, tuvimos que removerlo.

Un poco más hacia poniente, se ha construido un campanario exento. Al reconstruir la fábrica del siglo $\mathrm{X}$-una vez

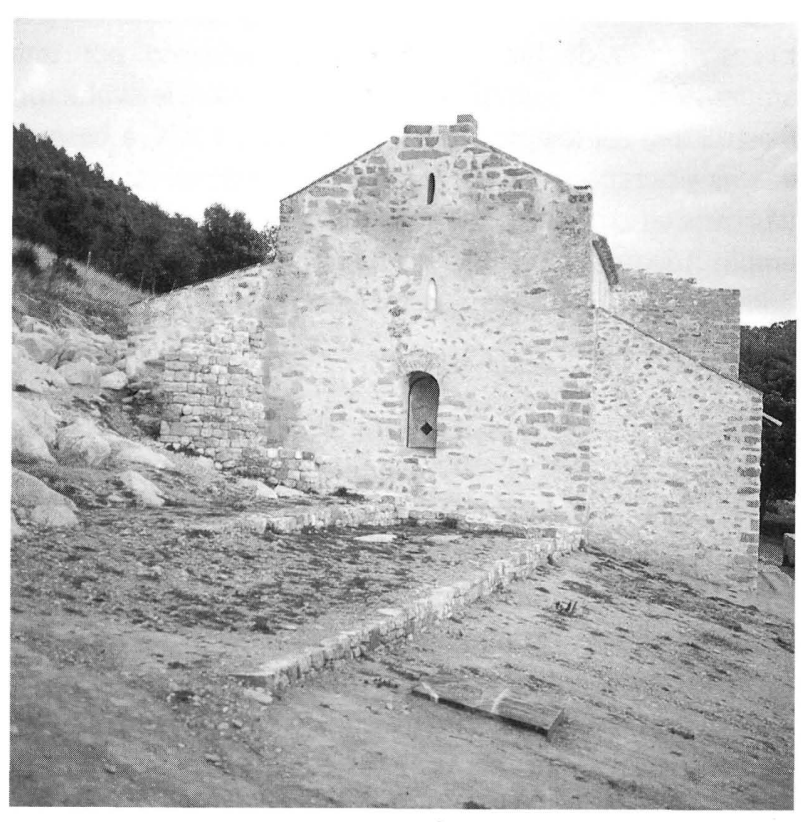

La iglesia vista desde poniente (7 de septiembre de 1995). 
desmontado el campanario del siglo XVIII- se renunció a colocar una espadaña, ya que científicamente era imposible, no sólo saber su morfología sino, incluso, su ubicación más probable. También, lógicamente, serenunció a reconstruir el arruinado campanario románico de torre. Pero como parecía improcedente dejar a la iglesia sin campanario, se decidió construir uno que por su situación y diseño explicara claramente su diacronía con el templo. El nuevo campanario está formado por dos triángulos metálicos unidos por uno de sus lados mayores, y se inclina, en actitud reverencial, hacia la iglesia. Como consciente de que su presencia pudiera importunar al visitante, el campanario le invita a acceder por una escalera a un balcón, desde el que podrá contemplar, sin interferencias, al único protagonista de aquel espacio, el templo prerrománico. La campana se acciona a distancia, desde la iglesia, y un mecanismo automático hace sonar el Ángelus cada día, a las doce del mediodía y a las siete de la tarde.

Los trabajos de la etapa de estudios técnicos y científicos, incluida la excavación arqueológica, se desarrollaron entre 1989 y 1992. Durante ese período la iglesia y su entorno permanecieron protegidos por una cerca provisional y por una cubierta sobre estructura de tubo metálico que permitío quelos trabajos arqueológicos no se vieran interrumpidos por las lluvias y que la cubierta del edificio pudiera desmontarse sin riesgo para el interior.

El 5 de noviembre de 1992 se inició la etapa de intervención arquitectónica, que se extendería, en diferentes fases, durante tres años. El 2 de noviembre de 1995, en el curso de la visita número 110 de la dirección facultativa, se dio por terminada la obra. Mes y medio antes, el tercer domingo de setiembre, coincidiendo con la tradicional romería en honor al santo, había sido reabierta la iglesia al público y celebrada la finalización de la restauración con distintos actos científicos, protocolarios y populares que tuvieron lugar en Berga y en el propio monumento. A lo largo de la obra arquitectónica se realizó un diario -que ocupa más de 120 folios-, en el que se comentan las reflexiones, dudas,

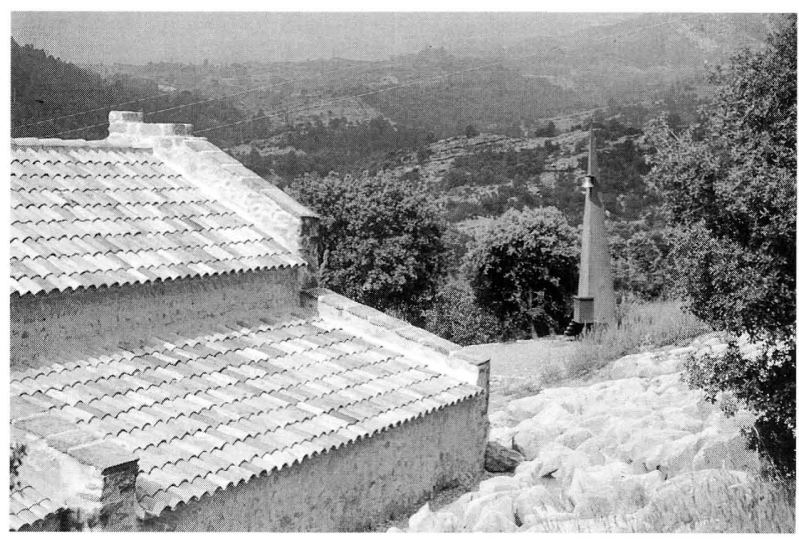

La iglesia vista desde el norte (7 de septiembre de 1995)

(c) Consejo Superior de Investigaciones Científicas Licencia Creative Commons 3.0 España (by-nc)

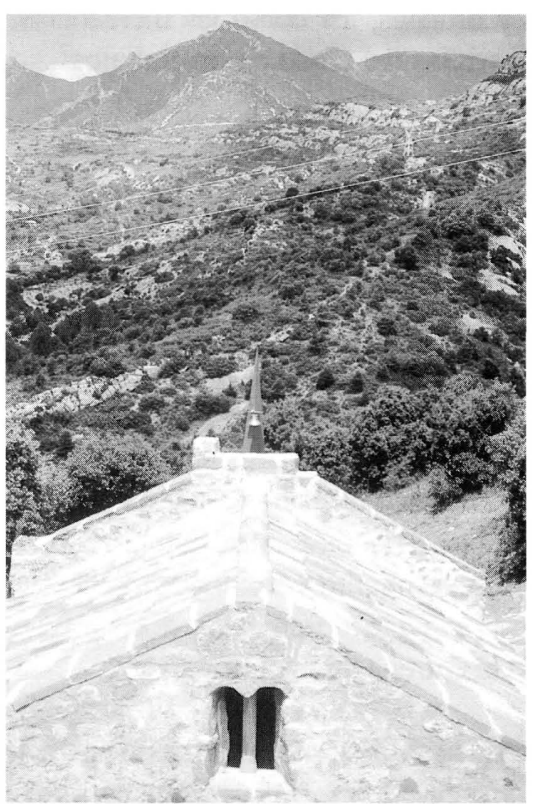

Vista del nuevo campanario que substituye a la desaparecida espadaña prerrománica, sólo insinuada en la restauración (26 de junio de 1995).

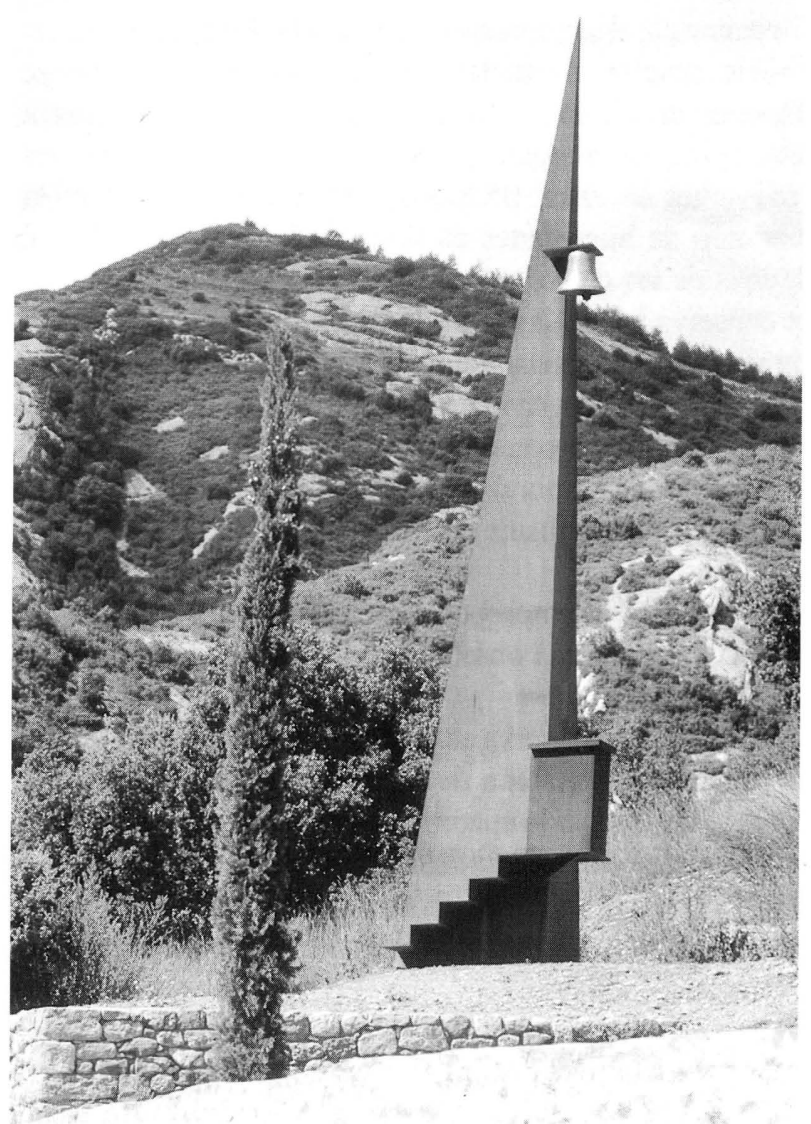

El nuevo campanario ( 7 de septiembre de 1995). 
discusiones y órdenes, así como las incidencias, visitas y otras circunstancias del curso de los trabajos ${ }^{7}$.

\section{TRABAJOS POSTERIORES DE CONTROL Y MANTENIMIENTO}

En la etapa V del "Método SCCM de restauración monumental" según el cual se programan y realizan las actuaciones del SPAL, se contemplan los estudios y trabajos posteriores al fin de las obras, tendentes a garantizar su buen mantenimiento. Fundamentalmente, son de dos tipos: los englobados en el denominado "Estudio After Ten" y los derivados del seguimiento continuado de la respuesta del edificio, especialmente durante los doce primeros meses posteriores a la entrega de la obra.

El primero de los estudios citados trata de analizar el estado de conservación del edificio una vez transcurridos diezaños. Se considera un estudio fundamental, no sólo para poder programar los trabajos de reparación que fueran necesarios, sino también para aprender de los errores o aciertos propios y para poder así ratificar o rectificar los criterios de intervención, las técnicas empleadas, la aplicación y uso de materiales no suficientemente experimentados, etc. En el caso de Sant Quirze no ha llegado aún el momento de realizar este estudio.

Sin embargo, el seguimiento continuado de la respuesta del edificio después de su restauración nos ha permitido ya disponer de algunos elementos de juicio sobre nuestra actuación. Al margen de otras posibles disfunciones irrelevantes ahora, el problema más grave detectado es la aparición de humedades en diversos lugares del edificio, algunas de las cuales pueden afectar a las pinturas murales conservadas o a las reproducidas. La aparición de estas filtraciones es especialmente notable en la parte alta de algunos muros de la nave central (sobre todo en el lugar que ocupan las pinturas románicas quefueron arrancadas y vueltas a colocar durante la obra) y en el paramento interior del muro de tramontana del ábside central.

De los estudios y comprobaciones realizados se han deducido inicialmente estas observaciones y conclusiones:

a) La cubierta se conserva en perfecto estado de estanquidad, por lo que la penetración de agua en las partes altas de los muros se ha producido aparentemente por empapamiento de éstos, posiblementea causa delluvias pertinaces acompañadas de fuertes ráfagas de viento, fenómeno atmosférico que se ha repetido en los dos últimos años con una frecuencia e intensidadinusitadas.

b) Era previsible que la filtración de agua en la parte baja del muro del ábside (cuyo nivel interior es inferior al del terreno) continuara después de la restauración, ya que éramos conscientes de las limitaciones del drenaje que dispusimos

(c) Consejo Superior de Investigaciones Científicas

Licencia Creative Commons 3.0 España (by-nc) tanto junto a este muro como a lo largo de la fachada norte. La naturaleza del terreno (rocas conglomeradas erosionadas por procesos cársticos) facilita la existencia de conducciones subterráneas por debajo de los drenajes, lo que dificulta impedir las humedades ascensionales procedentes de estas vías de penetración, favorecidas además por elhecho de que las cubiertas viertan las aguas junto a los muros, ya que por fidelidadhistórica renunciamos a recogerlasmediantecanales. Secontaba, por lo tanto, con quelos muros delasfachadas del lado norte mantuvieran (como a lo largo de los mil años de existencia del templo) un grado de humedad variable y por ello dispusimos la colocación de morteros y pinturas transpirables. Nunca intentamos "evitar las humedades", sino facilitar que el edificio conviviera con ellas.

c) La concentración y persistencia de las humedades en zonas próximas a las pinturas conservadas y restauradas nos hace suponer que este fenómeno no es ajeno a los procesos de restauración de estas pinturas y de los muros y morteros de soporte. En el caso del muro del ábside manejamos la hipótesis de que el relleno de las oquedades próximas a los frescos con poliuretano expandido haya sido un error, ya que pudiera ser esa la causa de que la evaporación de las aguas filtradas se concentre en los contornos de las pinturas, que pueden deteriorarse rápidamente por la cristalización de las sales transportadas.

d) Es prematuro avanzar unas soluciones definitivas a estos problemas detectados. En principio, se plantean en las direcciones siguientes: mejorar las condiciones de aireación del interior del edificio (que se ha manifestado insuficiente), lo que facilitará la convivencia de éste con las humedades procedentes del exterior; impermeabilización externa de algunos muros (siempre que se garantice la transpiración); eliminación del poliuretano expandido y sustitución por morteros; extremar la vigilancia del comportamiento del edificio y garantizar los trabajos de mantenimiento, que, en cualquier caso, se han demostrado una vez más absolutamente imprescindibles.

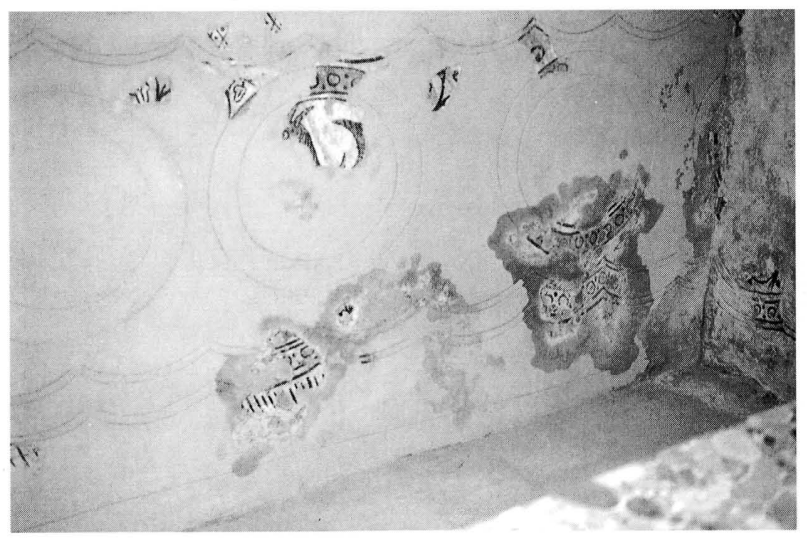

Las humedades aparecidas en el muro norte del ábside central (20 de septiembre de 1996). 
(1) J. Ainaud de Lasarte, Arte románico. Guía, Barcelona, 1973.

(2) J. Puig i Cadafalch, A. de Falguera i Sivilla, J. Goday i Casals, L'arquitectura romànica a Catalunya, I, Barcelona, 1909, p. $359,367-370$.

(3) C. Pallàs Arisa, "Arteprerrománico catalán: Pedret y Obiols" en San Jorge, n. 47, 1962, p. 63-67.

(4) A.González, "Restaurar monumentos, una metodología específica", Informes de la Construcción, n. 397, Madrid, septiembre-octubrede 1989.

(5) Los trabajos técnicos y científicos realizados con motivo de la restauración de Sant Quirze dePedret se refieren a los aspectos siguientes (no seincluyen los dictámenes previosy las memorias relativas a la excavación arqueológica y lostrabajos derestauración pictórica y escultórica):

Análisis histórico-arqueológico:

- Estudio derestos humanos(antropología física).

- Estudio ceramológico.

- Clasificación y estudio demonedas.

- Estudio de diversos materiales aparecidos en las excavaciones de 1960.

Análisis histórico-documental:

- Estudio de las fuentes documentales.

Análisis histórico-artístico

- Estudio de las pinturas murales.

- Estudio de la portada románica

- Inventarioy ánalisis artísticodeelementos de piedrahallados en

las excavaciones y durante las obras.
Análisis histórico-constructivo:

- Aproximación a la evolución constructiva del edificio a través del estudio de los materiales.

Análisis fisico-constructivo:

-Datos geográficos y ambientales del lugar.

- Determinación de la composición, análisis y diferenciación geoquímica entre morteros de diferentes etapas constructivas. - Informetécnico sobre el estado deconservación de la portada del siglo XIII.

-Estudio analítico demateriales inorgánicos.

Análisis arquitectónico:

- Levantamientotopográfico y fotogramétrico del conjunto. - Aproximación geométrica a la composición arquitectónica de la iglesia.

La mayor parte de estostrabajos se publicaron en los números 3, 4 y 6 de la serie Quaderns Científics i Tècnics, editada por la Diputación deBarcelona.

(6) A. González, "Especificidad y dificultad de la restauración de la arquitectura testimonial", en Actuacions en el patrimoni edificat: la restauració de l'arquitectura dels segles IX $\mathbf{i}$ X, Diputació de Barcelona, 1992.

(7) "Església de Sant Quirze de Pedret. Diari de les obres de restauració fet per l'arquitecte Antoni González del 5 de novembrede 1992 al 21 de juliol de 1994" (inédito).

\section{Ficha Técnica}

Realización: Diputación de Barcelona (Servicio de Patrimonio Arquitectónico Local). 1989-1995.

Investigación histórica: Arqueología: Alberto López Mullor y Alvar Caixal. Documentación, historia del arte y de la construoción: Anna Castellano, Raquel Lacuesta, Montserrat Hoja, M. Antònia Carrasco, Josep M. Moreno.

Intervención arquitectónica: Arquitecto: Antoni GonzálezMoreno-Navarro. Colaboradores: Xavier Guitart, arquitecto, Fina Gener y Jaume Bassas, arquitectos técnicos. Constructor: URCOTEX,I.SA (Cardona, Barcelona).

Trabajos especiales: Reproducción pintura mural: Emili Julià. Museización: Olga de la Cruz, Lourdes Borrell, Quim Boix.

Fotografias: Montserrat Baldomà. Dibujo: Txetxu Sanz, MaiteGómez 